\title{
Requirement of a corepressor for Dr1-mediated repression of transcription
}

\author{
Fred Mermelstein, ${ }^{1,5}$ Kam Yeung, ${ }^{1,5}$ Jun Cao, ${ }^{1}$ Juan A. Inostroza, ${ }^{1}$ Hediye Erdjument-Bromage, ${ }^{2}$ \\ Kathie Eagelson, ${ }^{3}$ David Landsman, ${ }^{4}$ Pat Levitt, ${ }^{3}$ Paul Tempst, ${ }^{2}$ and Danny Reinberg ${ }^{1,6}$ \\ ${ }^{1}$ Howard Hughes Medical Institute, Department of Biochemistry, Robert Wood Johnson Medical School, University of \\ Medicine and Dentistry of New Jersey, Piscataway, New Jersey 08854-5635 USA; ${ }^{2}$ Molecular Biology Program, Memorial \\ Sloan-Kettering Cancer Center, New York, New York 10021 USA; ${ }^{3}$ Department of Neurobiology, Robert Wood Johnson \\ Medical School, University of Medicine and Dentistry of New Jersey, Piscataway, New Jersey 08854-5653 USA; ${ }^{4}$ National \\ Center for Biotechnology Information, National Library of Medicine, National Institutes of Health, Bethesda, Maryland \\ 20894 USA
}

\begin{abstract}
A Dr1-associated polypeptide (DRAP1) was isolated from HeLa cells and found to function as a corepressor of transcription. Corepressor function requires an interaction between DRAP1 and Dr1. Heterodimer formation was dependent on a histone fold motif present at the amino terminus of both polypeptides. Association of DRAP1 with Dr1 results in higher stability of the Dr1-TBP-TATA motif complex and precluded the entry of TFIIA and/or TFIIB to preinitiation complexes. DRAPI was found to be expressed in all tissues analyzed with higher levels in tissues with a low mitotic index. Analysis of DRAP1 in the developing brain of rat demonstrated undetectable levels of DRAP1 in actively dividing cells but high levels of DRAP1 expression in differentiated non dividing cells. Dr1 was immunodetected in all cells analyzed. A model for DRAP1-dependent, Dr1-mediated repression of transcription is proposed.
\end{abstract}

[Key Words: Drl-mediated repression; corepression of transcription; HeLa cells; heterodimer formation]

Received January 3, 1996; revised version accepted March 7, 1996.

Studies aimed at understanding eukaryotic transcription have focused largely on identifying and characterizing RNA polymerase II and the general transcription machinery. To date, transcription of protein coding genes requires the concerted actions of six general transcription factors (GTFs) and RNA polymerase II (RNAPII) to accurately initiate RNA synthesis (Zawel and Reinberg 1993; Maldonado and Reinberg 1995). Of the six GTFs, TFID is the only one known to exhibit sequence-specific DNA-binding activity with an affinity for the TATA element (Topol and Parker 1984; Nakaiima et al. 1988; Buratowski et al. 1989|. TFIID exists as a large, multisubunit complex (Pugh and Tjian 1991; Gill and Tiian 1992), yet its DNA-binding activity is intrinsic to only one polypeptide of $38 \mathrm{kD}$, namely the TATA boxbinding protein (TBP) (Hoffmann et al. 1990; Kao et al. 1990; Peterson et al. 1990). The other components of the TFID complex are referred to as TAFs for TBP-associated factors (Dynlacht et al. 1991; Tanese et al. 1991; Zhou et al. 1992). The binding of TFIID to the promoter DNA is facilitated by TFIIA (Buratowski et al. 1989; Maldonado et al. 1990), which is thought to play an important role in the activation process $/ \mathrm{Ma}$ et al. 1993; Liberman and Berk 1994; Ozer et al. 1994; Sun et al.

\footnotetext{
${ }^{5} \mathrm{The}$ two first authors contributed equally to this work. ${ }^{6}$ Corresponding author.
}

1994; Yokomori et al. 1994) as well as in antirepression by removing inhibitory factors associated with TFIID (Meisterernst and Roeder 1991; Meisterernst et al. 1991; Cortes et al. 1992; Ma et al. 1993). Once bound to the TATA motif, TFIID serves as a beacon for the entry of TFIB (Buratowski et al. 1989; Maldonado et al. 1990). The resulting TFIID-TFIIB (DB) complex permits TFIIF to escort RNAPI to the promoter, resulting in the formation of DBPolF complex intermediate (Flores et al. 1990|. TFIIE, through interactions with the various GTFs (Maxon et al. 1994), is loaded on the promoter and recruits TFIIH (Flores et al. 1992). The complete DBPolFEH complex is then competent to initiate synthesis of RNA upon addition of ribonucleoside triphosphates (for review, see Zawel and Reinberg 1995). This highly ordered process may be facilitated by regulation of the various steps leading up to the formation of a transcription-competent complex. Recent studies have suggested an alternative pathway for preinitiation complex formation involving the recruitment of a preassembled RNA polymerase II holoenzyme to the promoter (Koleske and Young 1995; Ossipow et al. 1995).

The assembly of the GTF and RNAPII on class II promoters has allowed the identification of regulatory proteins that directly interact with the GTFs (for review, see Zawel and Reinberg 1995). These include a multitude of factors known as activators, coactivators, repressors, and most recently, corepressors of transcription /Herschbach 
and Johnson 1993; Johnson 1995). It has become apparent that transcriptional repression serves as a general mechanism to regulate the expression of a variety of genes in organisms ranging from yeast to humans. Repressors have been shown to be functionally important in mediating gene expression through a variety of mechanisms (for review, see Johnson 1995; Roberts and Green 1995). Repressors have been identified that function by virtue of their sequence-specific DNA-binding properties such as the Drosophila even-skipped protein (Johnson and Krasnow 1992|. A second class of repressors function independently of a direct interaction with DNA, but through protein-protein interactions such as the yeast Cyc8 (Ssn6) protein and Tup1, which are required for repression of genes regulated by glucose (Schultz and Carlson 1987; Trumbly 1992), oxygen (Zitomer and Lowry 1992), cell type (Mukai et al. 1991; Keleher et al. 1992), and DNA damage (Elledge et al. 1993). A second example includes Drosophila Groucho that upon interaction with the bHLH protein, Hairy, plays an important role during neurogenesis, segmentation, and sex determination (Paroush et al. 1994). Also, several of these regulatory proteins function both as activators and repressors. Examples include the Drosphila Krüppel protein (Sauer and Jackle 1993; Sauer et al. 1995), p53 (Seto et al. 1992), the Wilm's tumor gene WT1 (Maheswaran et al. 1993), the human thyroid hormone receptor, h-TR $\beta$ (Baniahmad et al. 1993), and the Rel family of proteins (Lehming et al. 1994).

We have previously identified one regulator known as Drl that can globally repress transcription of RNA polymerase II (Inostroza et al. 1992), and RNA polymerase III-transcribed genes (White et al. 1994). The importance of Drl function was revealed by virtue of it being an essential gene in yeast ( $\mathrm{S}$. Kim, J. Na, M. Hampsey, and D. Reinberg, unpubl.). As might be expected of a general repressor of transcription, overexpression of Drl resulted in lethality in yeast (S. Kim, J. Na, M. Hampsey, and D. Reinberg, unpubl.). It has been shown that the ability of Dr1 to repress RNA polymerase II transcription depends on its ability to interact with TBP and preclude the subsequent entry of TFIIA and/or TFIIB into the preinitiation complex (Inostroza et al. 1992; Kim et al. 1995). This prevents the formation of an active complex, and initiation by RNAPII (Inostroza et al. 1992). Similarly, RNAPIII transcription is inhibited by Drl through its interaction with TBP. The RNAPIII B-related factor (BRF), which contains homology to TFIIB, is blocked from interacting with TBP by Drl (White et al. 1994). Interestingly, the interaction of Drl with TBP can be disrupted to allow active transcription. This phenomenon was shown to be mediated by the adenovirus EIA I2S $_{12}$ product (Kraus et al. 1994). Finally, the ability of an activator to overcome Drl-mediated repression can vary depending on the class of activator. VP16-activated transcription can completely overcome Drl transcriptional repression. The glutamine-rich transcriptional activator SP1 can only mildly restore Drl-blocked transcription, whereas the proline-rich activator CTF was completely ineffective (Yeung et al. 1994).
In this paper we describe an approach taken that uncovered a unique mode of action for regulating Drl activity. Conventional chromatography coupled with immunoaffinity purification, using Drl antibodies, resulted in the purification of a repressor complex from HeLa cell extracts. We have characterized a component of this complex, termed Drl-associated protein 1 (DRAP1). Moreover, we have isolated the cDNA representing this protein and have shown that both recombinant and native DRAPl interact with Drl. This interaction results in a specific increase in transcriptional repression from the adenovirus major late promoter (AdMLP). DRAP1 represents a novel corepressor of transcription.

\section{Results}

\section{Identification of DRAP1}

We have shown previously that a number of phosphorylated polypeptides coimmunoprecipitate with Drl from HeLa cells using antibodies directed against Drl (Inostroza et al. 1992). One predominant phosphorylated polypeptide migrated at $\sim 28 \mathrm{kD}$ as determined by SDS-PAGE (Fig. 1A, lane 3). Coimmunoprecipitation of p28 by Dr1


Figure 1. Coimmunoprecipitation and immunoaffinity purification of DRAPs from HeLa cell nuclear extracts. $(A \mid$ Coimmunoprecipitation of Drl with DRAPl from HeLa cell extracts labeled with $\left[{ }^{32} \mathrm{P}\right.$ |orthophosphate in vivo. (Lane 1) Immunoprecipitation of Drl from boiled extracts with protein A-agarose and Drl antibodies. (Lane 2) Immunoprecipitation of Drl with protein A-agarose and Drl antibodies from untreated extracts in the presence of $0.1 \%$ SDS, and (Lane 3 ) in extraction buffer devoid of $0.1 \%$ SDS. Arrows depict Drl and DRAP1. Molecular weight markers are shown at left. (B) Purification of DRAP complexes from HeLa nuclear extracts. (Lane 1) Silver stain of recombinant Drl (50 ng); (lane 2) immunoaffinity-purified DRAPs derived from the $0.5 \mathrm{M}$ phosphocellulose fraction; (lane 3) immunoaffinity-purified complexes derived from the $1.0 \mathrm{M}$ phosphocellulose step of chromatography. Arrows at right identify DRAPl (top), ribosomal protein S9 (middle), and Drl (bottom). Markers are delineated at left. 
antibodies was dramatically reduced in the presence of SDS or when extracts were boiled (Fig. 1; lanes 1 and 2, respectively). These results indicate that p28 is immunoprecipitated by Dr1 antibodies due to an interaction between these two polypeptides (Drl and p28) and not because the anti-Drl antibodies recognize epitopes in p28.

To isolate Drl-associated polypeptides (DRAPs), protein fractions enriched in Drl were purified from HeLa cells by conventional chromatography and DRAPs were isolated on columns containing Drl antibodies. Drl-immunoreactive material derived from both the $0.5 \mathrm{M}$ and $1.0 \mathrm{M}$ phosphocellulose steps of chromatography were bound to the Drl antibody column and eluted with 100 $\mathrm{mm}$ glycine $(\mathrm{pH}$ 2.6). Glycine eluates were analyzed by SDS-PAGE followed by silver stain analysis, which revealed the presence of at least two different complexes. In the phosphocellulose $0.5 \mathrm{M}$-derived fraction, two predominant polypeptides were observed on SDS-PAGE; one migrating at $18 \mathrm{kD}$ identified as Drl by microsequencing, and a second unknown protein referred to as p28 migrating at $\sim 28 \mathrm{kD}$ (Fig. $1 \mathrm{~B}$, lane 2 ). From the phosphocellulose $1.0 \mathrm{M}$-derived fraction, several polypeptides were detected including a $30-\mathrm{kD}$ protein, a doublet of $\sim 23 \mathrm{kD}$, and a triplet of $\sim 20 \mathrm{kD}$. Microsequencing revealed that the $23-\mathrm{kD}$ polypeptides correspond to ribosomal protein $\mathrm{S} 9$, and the $20-\mathrm{kD}$ polypeptides correspond to different forms of Drl (Fig. 1). The band migrating at $\sim 30 \mathrm{kD}$ was found to be immunologically related to the $28-\mathrm{kD}$ polypeptide present in the $0.5 \mathrm{M}$-derived fraction (data not shown, see below). We termed the $28 \mathrm{kD}$ polypeptide DRAP1.

\section{Molecular cloning of DRAP1}

Immunopurified DRAP1 was digested with trypsin, and the resulting peptides were isolated by reverse phase chromatography. Four peptides were sequenced (Fig. 2A, a-d), and degenerative oligonucleotides based on the amino acid sequence from peptide $b$ were synthesized (see Materials and methods). Both HeLa cell and liver cell cDNA libraries were used to isolate cDNA clones for p28. The libraries were screened with the least degenerate oligonucleotide a. Two types of cDNA clones were isolated. The nucleotide sequence of the shorter cDNA clone derived from the HeLa cell library predicts an open reading frame encoding a polypeptide of 193 amino acids with a calculated $M_{\mathrm{r}}$ of 21.2. The second cDNA clone isolated from the liver cell library contains an insertion of 7 amino acids at residue 98 (Fig. 2A). This insertion appears to be attributable to alternative splicing, as analysis of the nucleotide sequence of a genomic clone demonstrates the presence of splicing acceptor and donor sites flanking the 7 amino acids (Fig. 2B). The isolated cDNA clones contained all of the DRAPl-derived peptides and each of the two clones encoded polypeptides interacting with Drl (see below). Analysis of the amino acid sequence of DRAP1 revealed extensive homology at the amino terminus with the yeast HAP5 protein (Fig. 2D). DRAPl was isolated as a Drl-binding protein, and our previous analyses demonstrated that the amino terminus of Drl contained homology to HAP3 (Inostroza et al. 1992). Both HAP3 and HAP5 polypeptides are known to form a complex ( $\mathrm{McNabb}$ et al. 1995). Our functional studies demonstrate that the HAP homology region present in Drl and DRAPl are important for the interaction of these polypeptides (see below). Moreover, included within the HAP homology region are residues that form a "histone fold" (Fig. 2C) (Baxevanis et al. 1995). The carboxyl terminus of DRAPl was found to be rich in proline residues (Fig. 2A,D).

\section{DRAP1 interacts directly with Dr1}

To analyze whether the isolated cDNA encoded DRAP1, the open reading frame was expressed in bacteria and the recombinant protein was isolated and used to produce antibodies. DRAPl purified from HeLa cells (see Materials and methods) migrated as a $28-\mathrm{kD}$ doublet on SDSPAGE (Fig. 3A, lane 3). The full-length recombinant polypeptide, which contained a histidine tag, migrated between the doublet (lane 4). In addition, a series of breakdown products, or premature terminated polypeptides, were also observed with the bacterially expressed protein (lane 4). Western blot analysis demonstrated that antibodies raised against the recombinant polypeptide recognized human DRAP1 (Fig. 3A, lane 1). The immunodetection was highly specific as the antibodies detected only the $28-\mathrm{kD}$ polypeptide in HeLa cell nuclear extracts (data not shown).

To further scrutinize the identity of the recombinant polypeptide, HeLa cell extracts prepared from metabolically ${ }^{32} \mathrm{P}$-radiolabeled cells were immunoprecipitated with anti-Drl (Fig. 3B, lane 1) or anti-p28 (Fig. 3B, lane 5) antibodies. Immunoprecipitated complexes were boiled, and a second immunoprecipitation was performed. As above (Fig. 1A), anti-Drl antibodies immunoprecipitated two predominant phospholabeled polypeptides, Dr 1 and DRAP1 (Fig. 3B, lane 1). Similar phospholabeled proteins were immunoprecipitated by antibodies directed against the recombinant DRAPl protein (Fig. 3B, lane 5). When boiled, immunopurified Drl complexes were incubated with DRAPl antibodies, DRAPl but not Drl was immunoprecipitated (Fig. 3B, lanes 2,3). Similarly, when boiled immunopurified DRAP1 complexes were incubated with Drl antibodies, Drl but not DRAPl was immunoprecipitated (Fig. 3B, lanes 6,7). In both cases, antibodies purified from preimmune serum failed to react with either Drl or DRAP1 in secondary immunoprecipitations (Fig. 3B, lanes 4,8). The results demonstrate that the isolated cDNA clones encode DRAP1.

We have demonstrated previously that Drl isolated from HeLa cells interacts with TBP to repress transcription and that this interaction also occurs when TBP is bound to the TATA motif, as different Drl-dependent DNA-protein complexes could be isolated using the gel mobility shift assay (Inostroza et al. 1992). Recombinant Drl ( $\mathrm{rDr} 1)$ could also interact with TBP. However, in the presence of DNA, rDrl and TBP cannot form a ternary complex that could be resolved using the gel mobility 
Figure 2. Structural features of human DRAP1. (A) Nucleotide sequence of a cDNA encoding DRAP1. The sequence is listed using the single-letter amino acid code. Amino acids underlined represent peptide sequence derived from microsequencing of human DRAPl protein purified from HeLa nuclear extract. $(\triangle)$ The site of a 7-amino acid insert found in the cDNA isolated from a human liver cDNA library. $(B)$ Partial sequence of a genomic clone of DRAP1 isolated from the HeLa genomic library. The sequence around the point of insertion is shown. Exon sequences are underlined (broken line), and the donor and two downstream acceptor sites of the intron are in bold face type. The additional 7 amino acids that are present in the human liver cDNA are underlined. $(C)$ Multiple sequence alignment of several proteins containing the histone fold aligned to all four core histones. The sequences were detected with the MOST software using an alignment box of a nonredundant data set containing 268 histone sequences. The boxed region corresponds to the histone fold, and at each position, residues in agreement with any of the core histones are shown in inverse type. The $r$-values for each of the nonhistone sequences are shown. The accession numbers obtained from the histone sequence database at National Center for Biotechnology Information (NCBI) (Baxevanis 1995) for human H2A.l, human $\mathrm{H} 2 \mathrm{~B}$, human $\mathrm{H} 3.1$, human $\mathrm{H} 4$, rat $\mathrm{CBF}-\mathrm{C}$, and yeast Hap5P are sp|PO2261, sp|P33778， sp|P16106， sp|PO2304， gp|U17607, and sp|Q01658, respectively. (D) Schematic representation depicting the structural features of DRAP1. Shown is the nucleotide sequence of a cDNA encoding DRAPl derived from clones isolated from a HeLa cell cDNA library. The nucleotide sequence of DRAP1 predicts a long open reading frame encoding a polypeptide of 193 amino acids with a calculated molecular mass of $21.3 \mathrm{kD}$. The amino acid sequence was analyzed using the Wisconsin Sequence Analysis Package, Genetics Computer Group (University Research Park, Madison, WI). Analysis of the amino acid sequence of DRAPl reveals two interesting features: (1) The shaded area at left shows a region homologous to HAP5/CBF-C containing a histone fold motif (see below); and (2) the shaded area at right indicates a prolinerich region.
A

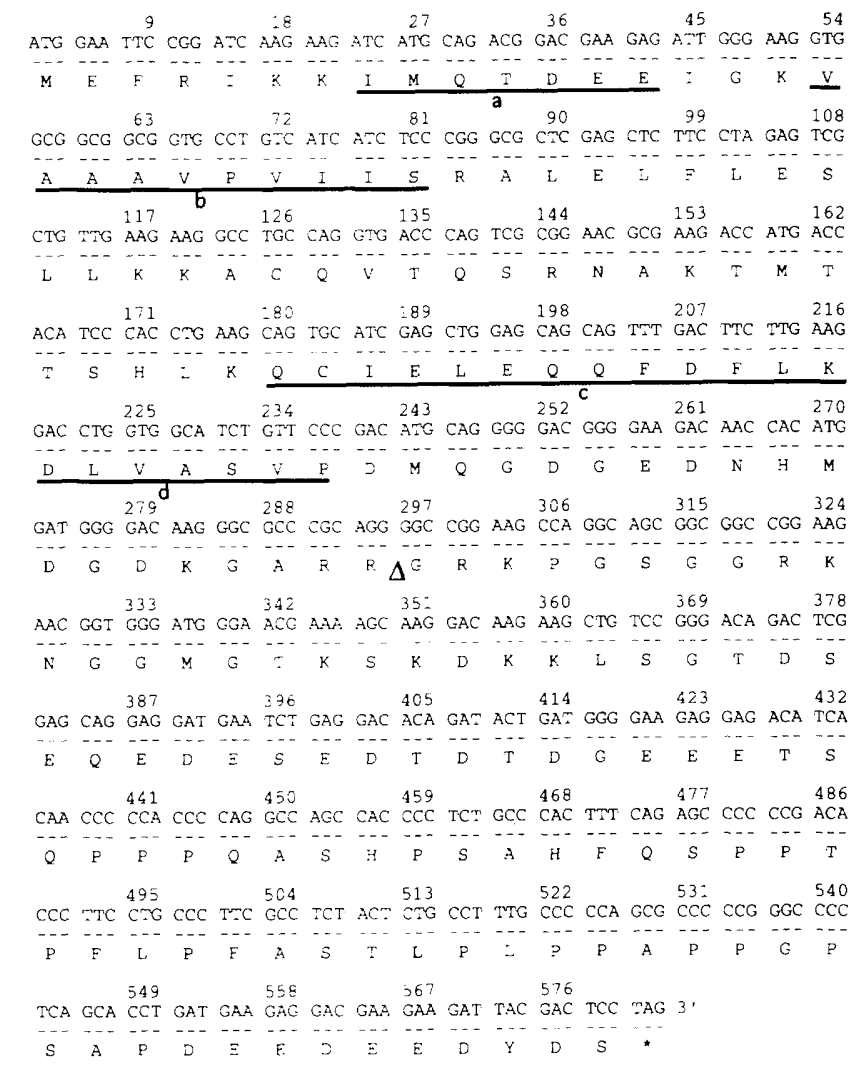

B

GCC CGC AGG TGG GGC CAG GGL CTG GCA taC AGt GGC GAa GGC CAA GGC ACA GGC
A
CTT GGG GGT GGC CAA GGA GTA GGG AGC ACT CCG GGC $\mathbf{A G}_{\text {A }}$ TGG ACT GTA CCT TCC W

CAA AGG GGC CGG AAG 3 .

$\underline{Q^{2}} \mathrm{R}^{\mathrm{R}} \mathrm{K}$
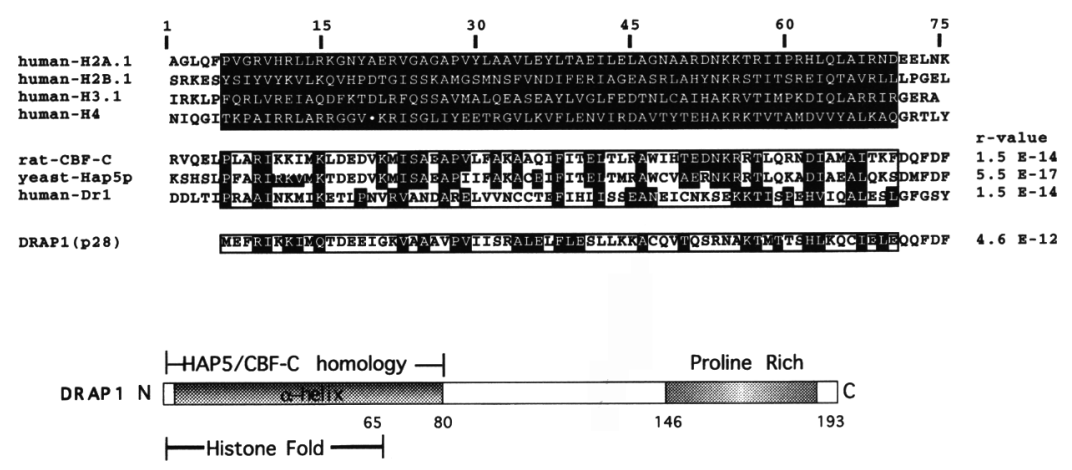

shift assay, as with native Drl. Because of the differences observed in the recombinant and native Drl protein, we analyzed the effect of rDRAP1 on the TBP-rDrl complex using a DNA fragment containing the AdMLP in a gel mobility shift assay. Under the conditions used, TBP, rDRAP1, or rDrl failed to form a DNA-protein complex independently (Fig. 3C). Moreover, in agreement with our previous observations, we were unable to demon- 
A

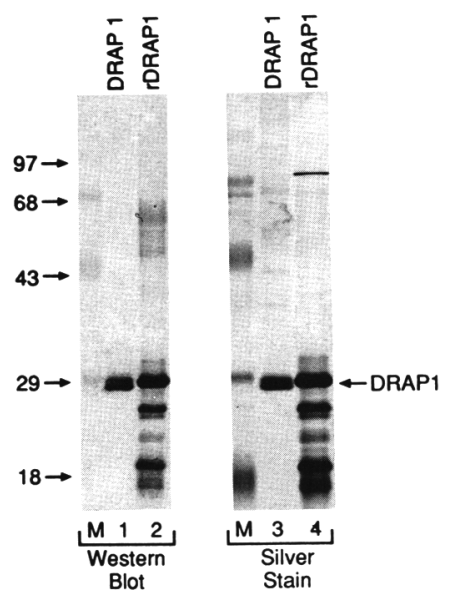

B

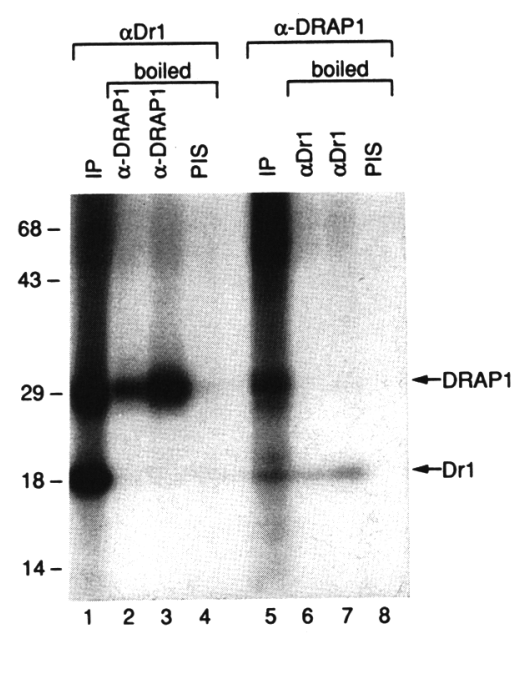

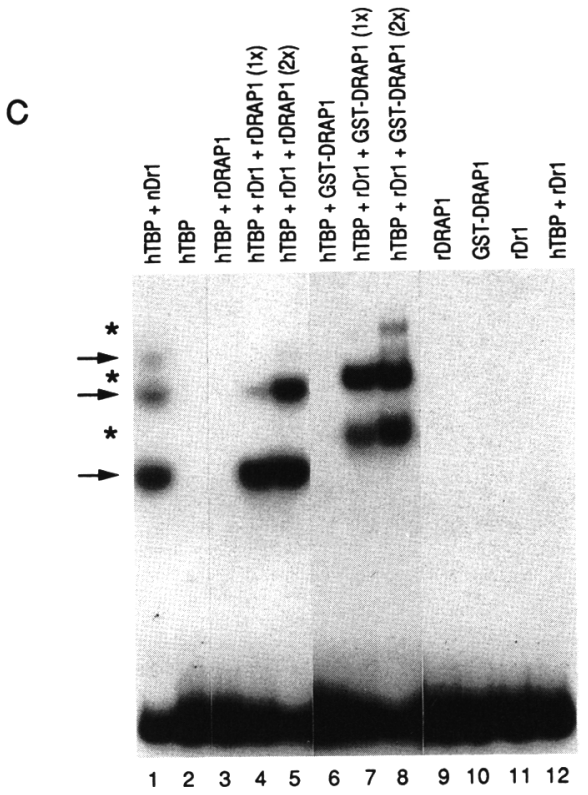

Figure 3. DRAPl interacts with Drl both in vivo and in vitro. $|A|$ Western blot and silver stain analyses of human DRAP1 and recombinant histidine-tagged DRAP1. Immunoaffinity-purified DRAPI (lane 1) and recombinant DRAP1 (lane 2) were resolved by $12.5 \%$ SDS-PAGE, and proteins were either transferred to nitrocellulose membrane or analyzed by silver stain. Blots were developed using affinity-purified DRAPl antibodies and developed using anti-rabbit antibodies conjugated to alkaline phosphatase with Nitro Blue Tetrazolium (NBT) and 5-bromo-4-chloro-3-indolyl phosphate (BCIP). (Lane 3) Silver stain analyses of immunoaffinity-purified DRAPl and (lane 4) recombinant DRAP1. Molecular weight markers are indicated (M) at left. (B) Coimmunoprecipitation of Drl with DRAPl from HeLa extracts using antibodies raised against recombinant DRAPl and Drl. Drl coimmunoprecipitates with DRAP1 from HeLa cells labeled with ${ }^{32} \mathrm{P}$ ]orthophosphate in vivo. (Lanes 1-4|Immunoprecipitation of Drl and DRAPl from whole cell extracts with protein A-agarose and Drl antibodies. The immunoprecipitated complexes were either untreated (lane 1 ) or boiled to dissociate the complexes. The boiled eluates were subsequently immunoprecipitated with protein A-agarose and DRAP1 antibodies (lane 2, 1 $\mu \mathrm{g}$; lane 3,5 $\mu \mathrm{g}$ ) or with preimmune serum (lane 4,5 $\mu \mathrm{g}$ ). (Lanes 5-8) Immunoprecipitation of Drl and DRAP1 from whole cell extracts with protein A-agarose and DRAP1 antibodies. The immunoprecipitated complexes were either untreated (lane 5) or boiled to dissociate the complexes. The boiled eluates were subsequently immunoprecipitated with protein A-agarose and Drl antibodies $(1 \mu \mathrm{g}$, $5 \mu \mathrm{g}$ ) (lane $6,1 \mu \mathrm{g}$; lane 7,5 $\mathrm{g}$ ) or with preimmune serum (lane 8,5 $\mu \mathrm{g}$ ). Arrows depict Drl and DRAP1. Molecular weight markers are shown at left. $|C|$ DRAP1 is contained in TBP-Drl complexes and required for higher order complex formation. DNA-protein complexes were formed on the AdMLP and analyzed using the gel mobility shift assay. Binding reactions were performed using a 3 '-end-labeled DNA fragment containing AdMLP $\mid-40$ to + 15). hTBP-Drl-DRAP1 complexes were formed using human histidinetagged TBP (7.5 ng), rDrl (25 ng), histidine-tagged DRAPl (0.25 or $2.5 \mathrm{ng}$ ), or GST-DRAPl (0.5 or $5 \mathrm{ng})$. Different complexes formed are indicated by arrows at left. Asterisks denote slower migrating complexes formed in the presence of the GST-DRAPI fusion protein.

strate a rDrl-TBP-TATA complex. However, the addition of increasing concentrations of rDRAPl to reactions containing rDrl and TBP resulted in the formation of DNA-protein complexes that comigrated with complexes formed with native Drl (containing DRAP1) (Fig. 3 C). As demonstrated previously, all of these complexes contained TBP and Dr1, as specific antibodies to TBP or Drl supershifted the complexes (data not shown; see Inostroza et al. 1992). Moreover, these complexes also contained DRAP1, as demonstrated by supershift experiments using anti-DRAPl antibodies (data not shown) or a GST-DRAPl fusion protein. The larger GST-DRAP1 fusion protein retarded the mobility of the different DNA protein complexes (Fig. 3C, cf. lanes 4 and 5 with 7 and 8 |. Moreover, recovery of the proteins from each of the complexes, followed by Western blot analysis, demonstrated the presence of TBP, Drl, and DRAPl in each complex (data not shown). Thus, DRAP1, together with
TBP and Drl, are integral components of the different DNA-protein complexes. DRAP1 appears to stabilize the TBP-Drl-DNA complex.

\section{DRAP1 is a corepressor required for Dr1-mediated repression of transcription}

To determine whether DRAPl could have an effect on transcription or on Drl-mediated repression, recombinant DRAPl was added to transcription reactions in a system reconstituted with GTFs, RNAPII, and the AdMLP in the presence and absence of recombinant Drl. DRAP1-enhanced, Dr 1-mediated repression can be demonstrated at a concentration of Drl that reduces transcription from AdMLP by $10 \%$ (Fig. 4, lanes 3-5). At the highest concentration of DRAPI, $\sim 90 \%$ of the transcription activity from AdMLP was repressed. DRAP1 in the 
A
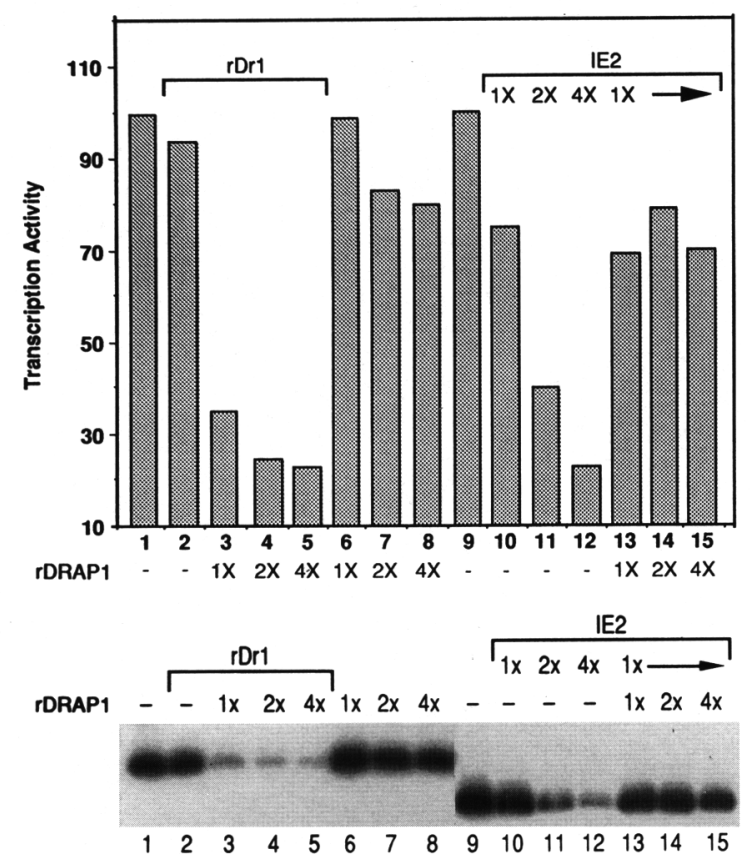

B
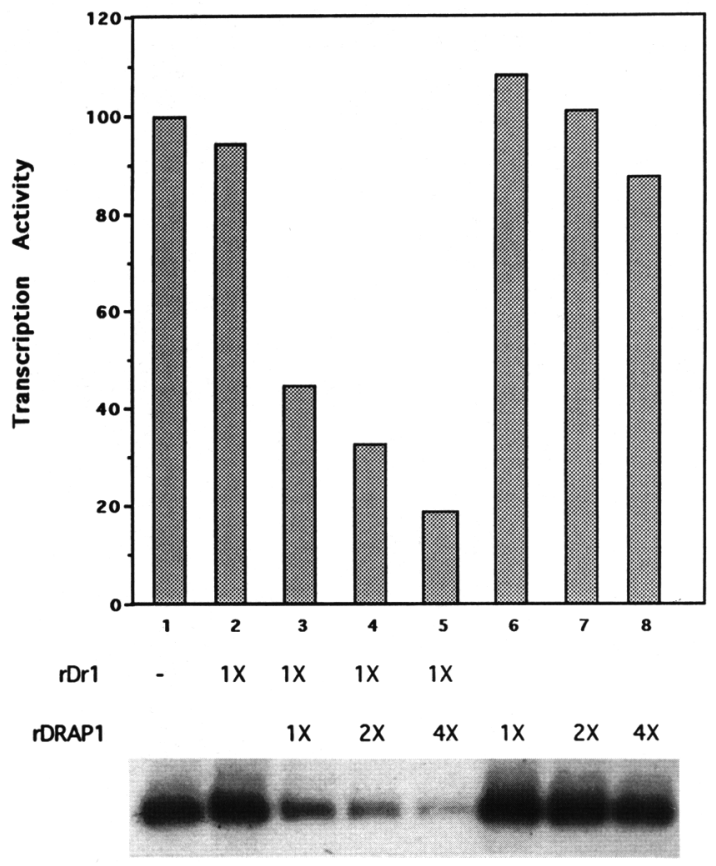

Figure 4. DRAPl specifically enhances Drl-mediated repression. $|A|$ DRAPl enhancement of Drl-mediated repression in the presence of TBP. (Top) Bar graph representing transcription activity of transcription reaction mixtures containing AdMLP reconstituted using purified or recombinant general transcription factors, RNA PII is shown with increasing amounts of DRAPl as indicated $(1 \times=5$ $\mathrm{ng}$ ), in the presence of $\mathrm{rDr} 1$ (375 $\mathrm{ng}$, lanes 2-5) or absence of $\mathrm{rDrl}$ (lanes 1,6.7,8). (Lanes 10-12) Effect of the CMV IE2 repressor (1 $\times=50$ $\mathrm{ng}$ ) in transcription reactions in the presence of different amounts of DRAPl $\mid \mathbf{1} \times=5 \mathrm{ng}$, lanes 13-15| or absence of DRAP1. (Lanes 1,9| Basal transcription reactions in the absence of any repressor. Transcription activity was quantified on a PhosphorImager (Bio-Rad). (Bottom) Autoradiograph of RNA transcripts from transcription reactions quantified in the bar graph above. (B) DRAPl enhancement of Drl-mediated repression in the presence of TFIID. (Top) Bar graph representing transcription activity of transcription reaction mixtures containing AdMLP reconstituted using purified RNA PII, TFIIH, recombinant general transcription factors TFIIB, TFIIE, and TFIIF, as described above in $A$, but with eTFIID $(2.5 \mathrm{ng})$ in place of TBP, with rDrl $\mid 375 \mathrm{ng}$, lanes 2-5), or without rDr1 (lanes $1,6,7,8\}$ in the presence of the different amounts of rDRAPl $\mid 1 \times=5 \mathrm{ng}$, lanes 3-8|. Transcription activity was quantified on a PhosphorImager (Bio-Rad). (Bottom) Autoradiograph of RNA transcripts from transcription reactions represented in bar graph above.

absence of Dr1 had no appreciable effect on transcription (Fig. 4; data not shown; see below). DRAP1 enhancement of Drl-mediated repression was also observed in the presence of TAFs (i.e., when TFIID replaced TBP) (Fig. 4B).

To determine the specificity of DRAP1 function, we studied its effect on the cytomegalovirus (CMV) immediate early (IE) 2 repressor protein. It has been demonstrated that CMV-IE2 can repress class II promoters via a cis-acting repressor element (CRE) positioned proximal to the transcription start site (Liu et al. 1991). CMV-IE2mediated repression has been shown in vitro using purified RNAPII, GTFs, and the Ad-MLP containing a CRE (Lee et al. 1996). Using this template, recombinant IE2 repressed transcription in a dose-dependent manner (Fig. 4A, lanes 9-12) and required the presence of a CRE site (data not shown). The repression activity of IE2 was not affected by the presence of DRAP1 (Fig. 4A, lanes 13-15) even though the same amount of DRAPl could drasti- cally enhance Drl-mediated repression (Fig. 4A, lanes $2-51$.

Interaction of DRAP1 with Dr1 is required for the enhancement of Dr1 repression

The primary sequence of DRAPl revealed a region of homology to HAP5/CBF-C (CAAT-binding factor-C), and within this region a histone fold motif was identified (Fig. 2). Interestingly, the primary sequence of Drl revealed a region of homology to HAP3/CBF-A (Inostroza et al. 1992), and also within this region a histone fold motif is found (Fig. 2, Baxevanis et al. 1995). Because the histone fold motif is thought to be a determinant for protein-protein interaction (Baxevanis et al. 1995), and because it is known that HAP5/CBF-C interacts with HAP3/CBF-A, we analyzed the Drl-DRAP1 interaction using recombinant proteins purified from Escherichia coli. The interaction of rDRAPl with rDrl was dose- 
dependent as measured by surface plasmon resonance (Fig. 5B). After establishing the interaction of DRAP1 with $\operatorname{Drl}$, we subsequently analyzed the domains contained within DRAPl required for this interaction. When the first amino-terminal 23 amino acids were removed from DRAPl (N23), binding was mildly reduced (Fig. 5C). Further deletion of the amino-terminal 80 amino acids of DRAP1 (N80) completely abolished binding (Fig. 5C). Similarly, upon truncation of 92 amino acids from the carboxyl terminus of DRAP1 (C101), which contains the proline-rich region, binding was not observed (Fig. 5C).

To correlate whether the binding of DRAP1 to Drl was required for the enhancement of Drl-mediated repression, the effects of different truncated mutants were assayed in the reconstituted transcription system. The result of one representative assay is shown in Figure 5 $(\mathrm{D}, \mathrm{E})$. Deletion of amino acids 144-193 (C144) had no effect on the ability of DRAP1 to enhance Drl-mediated repression of transcription (Fig. 5D, lanes 4-6). However, removal of amino acids that are required for the interaction with Drl (mutant N80 or C101), completely abolished the activity of DRAPI (Fig. 5, D, lanes 7-9, and E, lanes 7-9). Removal of the first 23 amino acids of DRAP1 (mutant N23) completely abolished its activity (Fig. 5E, lanes 4-6). However, this mutant still maintained its ability, although to a reduced level, to interact with Drl.

\section{The histone fold/HAP3 motif of Dr1 is required} for the interaction with DRAP1

The amino terminus of Drl contains a histone fold/ HAP3 motif; therefore, it was of interest to determine whether this region is important for interaction with DRAP1. The interaction was analyzed using Drl glutathione $S$-transferase (GST) fusion proteins (GST, GSTDr1, and GST-Drl $\Delta 1-70$ ) in a pull-down assay. The proteins were purified as described, and equal amounts of each fusion protein were immobilized on glutathioneagarose columns. The ability of different columns to retain reticulocyte lysate-transcribed/translated ${ }^{35} \mathrm{~S}$-labeled hTBP or DRAPl was monitored by fluorography. As shown in Figure 6B, a GST-Drl, but not a GST column, retained $>20 \%$ of the DRAPl input. In contrast, removal of the first 70 amino acids of Dr1 (Dr1 $11-70)$, which includes histone fold/HAP3, completely abrogated the binding of DRAP1 to Drl (Fig. 6B, lane 8). The inability of the GST-Drl $\Delta 1-70$ column to retain any DRAPl was not attributable to an inactive protein preparation, as a considerable amount of hTBP was retained (Fig. 6B, lane 5). The TBP-binding domain is located between residues 80-100 in Drl (Yeung et al. 1994).

To further determine whether there is a direct correlation between binding of Drl to DRAP1 and repression enhancement, we studied the effect of DRAP1 on Drl $\Delta$ 1-70-mediated repression of transcription in vitro. Consistent with our previous observations, we found that $\mathrm{rDrl}$ could repress transcription, although a higher concentration of recombinant polypeptide was found to be required (Inostroza et al. 1992, Yeung et al. 1994). Under these conditions we found that the amino terminus of Dr1 is dispensable for Drl-mediated repression of transcription (Fig. 6C, lanes 2-4, also, see Yeung et al. 1994). However, unlike its wild-type counterpart, the repression activity of Dr1 $\Delta 1-70$ remained unaffected in the presence of DRAPl (Fig. 6C, lanes 5-7). Thus, these results demonstrate further that DRAP1-mediated enhancement of repression of transcription requires direct interaction with Drl.

\section{The association between Dr1 and DRAP1 is required for efficient disruption of the TBP-TFIIA-TATA complex}

Our previous studies have indicated that Drl prevented the association of TBP with TFIIA and/or TFIIB (Inostroza et al. 1992). We analyzed the effect of DRAP1 in Drl-mediated disruption of the TBP-TFIIA (TA) complex using the gel mobility shift assay. The TA (TBP-TFIIA) complex was formed on the AdMLP under conditions where $\sim 95 \%$ of the DNA fragment was in the complex and different combinations of Drl/DRAPl were added (Fig. 7A). Although the addition of DRAPl (lane 13) or Drl (lane 2) to the TA complex was without an appreciable effect, the addition of both factors, DRAPl and Drl, resulted in displacement of the TA complex with the appearance of the characteristic TBP-Drl-DRAP1 complexes (Fig. 7A). Effective displacement of the TA complex required both Drl and DRAPl in approximately equimolar amounts (lane 8). Decreasing the amount of Drl (from lanes 9 to 13), or of DRAPl (from lanes 7 to 2), resulted in the reappearance of the TA complex. Identical results were observed when the TB (TBP-TFIIB), or TAB (TBP-TFIIA-TFIIB) complexes were analyzed (data not shown).

To analyze whether a correlation between repression of transcription and displacement of TFIIA (or TFIIB) from the TA (or TB or TAB) complex exists, different DRAPl mutants were analyzed. DRAPl mutants that were defective in enhancing Drl-mediated repression of transcription (N23, N80, and C101) were also defective in their ability to displace TFIIA from the TA complex (Fig 7B). Thus, these results demonstrate that displacement of TFIIA (or TFIIB) from the TA or TAB complex correlated with the formation of Dr1-DRAP1-TBPDNA complexes and with repression of transcription.

Interestingly, the association of Drl and DRAP1 with the TBP-DNA complex did not result in the formation of a single discrete complex but in a series of complexes (Figs. 3C and 7). In light of the histone fold motif present at the amino terminus of Drl and DRAP1, we were interested in further analyzing this phenomenon. We observed that the appearance of the different complexes correlates with the concentration of Drl and DRAP1 (Fig. $7 \mathrm{C}$ ). At limiting concentrations of Drl (but saturating amounts of DRAP1), a faster-migrating single complex was observed (complex 1). Increasing the concentration of Drl resulted in the formation of the slower-mi- 
Figure 5. The histone fold region of DRAP1 is required for interaction with Drl and enhancement of Dr1-mediated repression. $(A)$ Schematic representation of DRAPl showing structural features including the HAP5 homology domain (shaded bar), proline-rich region (solid bar), and the histone fold. Various truncations of both carboxy- and amino-terminal amino acids are shown below. Ability to bind Drl is indicated at right. $(B)$ Sensorgram representing a dose-dependent interaction of rDRAPl with $\mathrm{rDrl}$ as detected by surface plasmon resonance. rDRAP1 (1.6, $3.3 \mathrm{ng}$, and $5.0 \mathrm{ng}$ ) binds to surface-immobilized rDrl $(0.6 \mu \mathrm{g})$ (see Materials and methods). The net change in the baseline from before to after sample injection, in resonance units (RUs), indicates binding of proteins to the surface immobilized rDrl. (X) Resonance signals measured before and after injections. (S) Time at which $0.05 \%$ Sarkosyl washes were performed. (C) Sensorgram representing the interaction of DRAP1 mutants (N80, N23, and C101) with $\mathrm{rDrl}$ by surface plasmon resonance. rDRAP1 (10 ng) is used as a positive control. Plasmon resonance experiments were performed as described in $B .|D|$ The carboxy-terminal region of DRAP1 is dispensable for the corepression activity of DRAP1. (Top) Graphic representation of transcription activity of transcription reaction mixtures containing AdMLP reconstituted using purified or recombinant general transcription factors, RNA PII, and rDrl (375 ng), rDRAP1 (20 ng), or different amounts of rDRAPl mutants C144 and $\mathrm{Cl01}(5,10$, and $20 \mathrm{ng})$, as indicated. Transcription activity was quantified on a PhosphorImager (Bio-Rad). (Bottom) Autoradiograph of RNA transcripts from transcription reactions represented in bar graph. $(E)$ The histone fold/HAP5 region of DRAP1 is required for the corepression activity of DRAPl. (Top) Graphic representation of transcription activity of transcription reaction mixtures containing

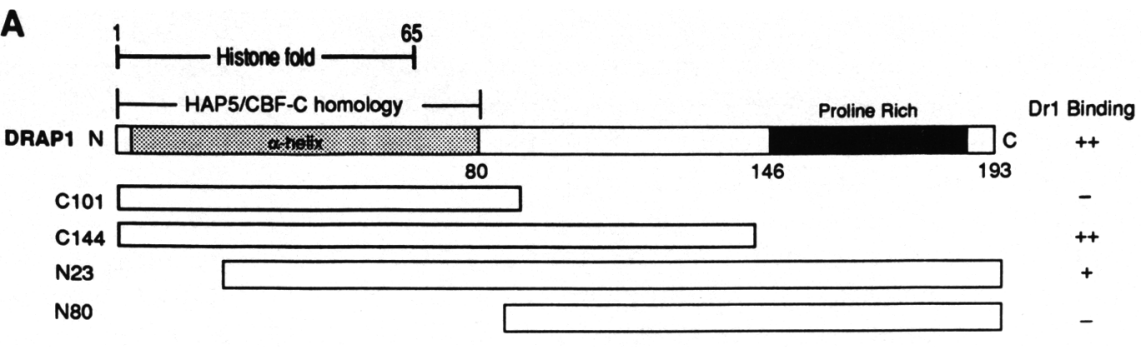

B
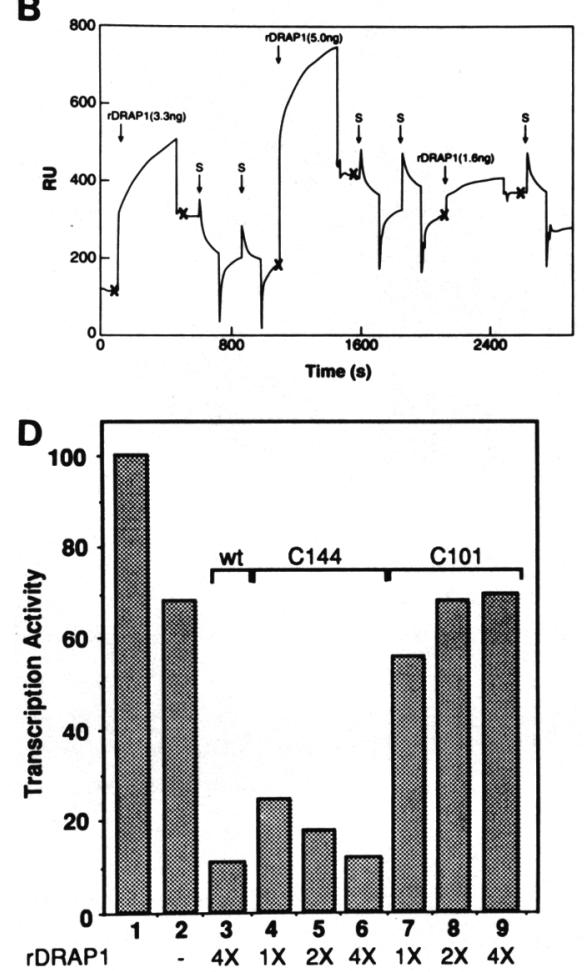

rDr1 - 1

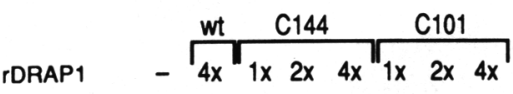

rDr1 -

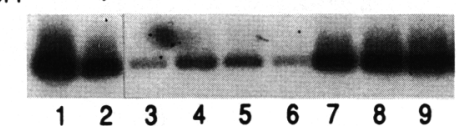

C
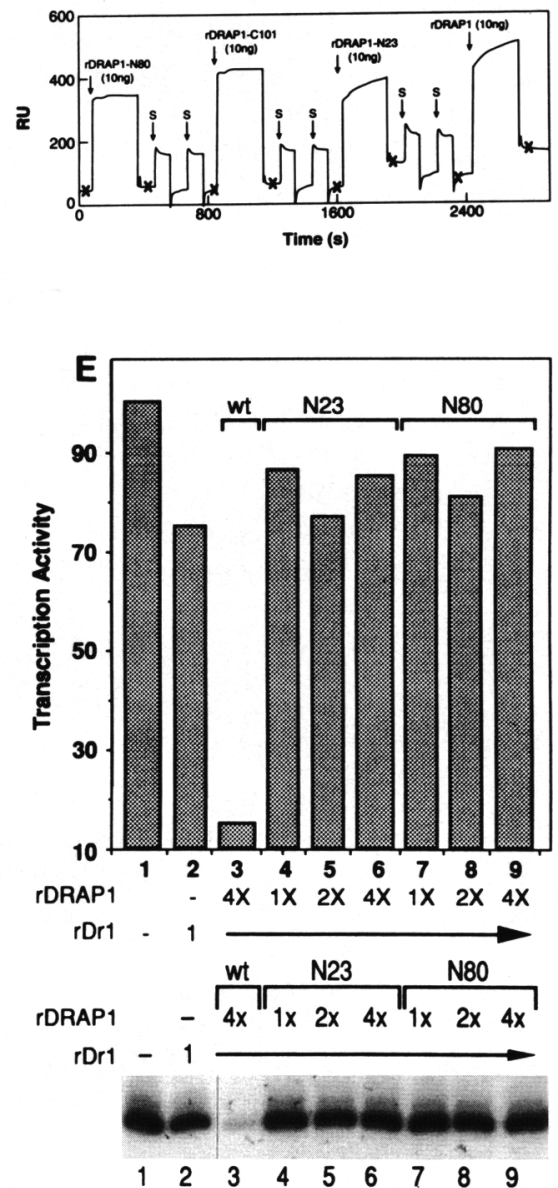

AdMLP reconstituted using purified or recombinant general transcription factors, RNA Polymerase II, and rDrl (375 ng) rDRAPl (20 $\mathrm{ng}$, or different amounts $(5,10$, and $20 \mathrm{ng})$ of rDRAP1 mutants $\mathrm{N} 23$ and N80, as indicated $(1 \times, 2 \times$, or $4 \times$, where $1 \times=5 \mathrm{ng})$. Transcription activity was quantified on a PhosphorImager (Bio-Rad). (Bottom) Autoradiograph of RNA transcripts from transcription reactions represented in bar graph.

grating complexes, up to four different ones (Figs. 3C and 7C). The formation of the slower-migrating complexes was also dependent on the concentration of DRAP1, as reducing the concentration of DRAP1 also reduced the amount of slower-migrating complexes. Formation of the different complexes appears to be an ordered phenomenon, where complex 1 is formed first and used to produce complex 2 and so on (Fig $7 \mathrm{C}$ ). The polypeptide composition in each complex was analyzed by extracting the proteins from the different complexes. This analysis indicated that all the complexes contained Dr1, DRAP1, and TBP (data not shown). We next analyzed the DNase I footprinting pattern obtained at two different concentrations of Dr1-DRAP1 using equimolar amounts of Dr1 and DRAP1. Nucleotides extending from approximately -39 to -15 were protected from DNase I cleavage by the binding of TBP to the AdMLP-TATA motif (Fig. 7D, lane 2). Interestingly, the addition of Drl-DRAPl complex to the TBP-TATA complex resulted in a reduction of the area covered by TBP on the TATA motif as well as 
A

$\operatorname{Dr} 1$

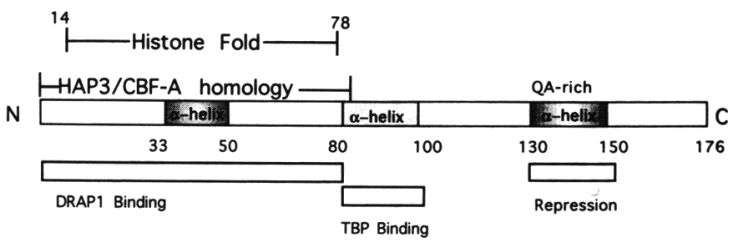

B

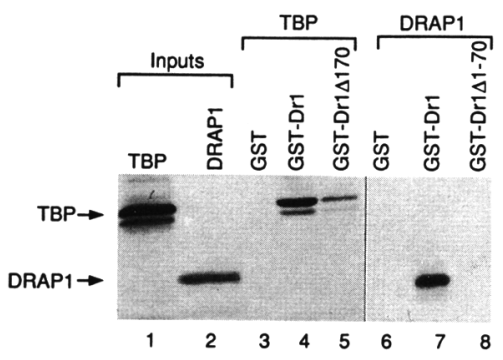

C

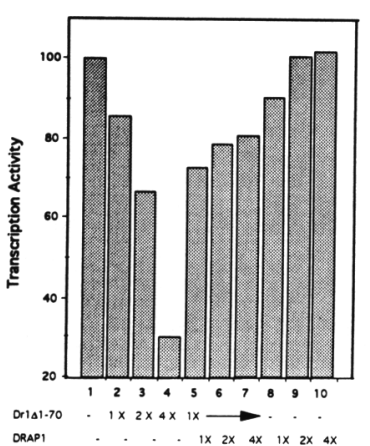

D



Figure 6. The Histone Fold region of $\operatorname{Dr} 1$ is required for interaction with DRAP1. (A) Schematic representation of Drl showing regions integral for its interaction with DRAP1 (1-80), binding of TBP $(80-100)$, as well as a region mediating Drl repression activity (130-150, glutamine-alanine rich region). The schematic also indicates the location of the histone fold (14-78). $\alpha$-Helical regions of Drl are shown in the shaded areas. Numbers indicate amino acid positions in the Drl protein. $(B)$ The histone fold region of Drl is required for interaction with DRAPl in a GST pull-down assay. $\left[{ }^{35} S \mid\right.$ Methionine-labeled human TBP and $\left[{ }^{35} S\right]$ methionine-labeled DRAPl were produced by in vitro transcription/translation, and equal amounts (inputs), were incubated with either GST $(1 \mu \mathrm{g}$, lanes 3,6$)$, GST-Drl (1 $\mu \mathrm{g}$, lanes 4,7$\}$, or GST-Drl $\Delta 1-70\langle 1 \mu \mathrm{g}$, lanes 5,8) linked to glutathione-agarose beads for $1 \mathrm{hr}$, followed by extensive washing. The bound proteins were eluted in SDS-PAGE buffer, resolved by $12 \%$ SDS-PAGE, and visualized by fluorography. $|C|$ The enhancement of Drl repression by DRAPI is directed through the histone fold region of Drl. The bar graph represents transcription activity of transcription reaction mixtures containing AdMLP reconstituted using purified or recombinant general transcription factors, RNA PII, and different amounts of DRAP1 15,10 , and $20 \mathrm{ng})$ or $\operatorname{Dr} 1 \Delta 1-70(100,200$, or $400 \mathrm{ng})$ as indicated $(1 \times, 2 \times$, or $4 \times)$. Transcription activity was quantified on a PhosphorImager (Bio-Rad). (D) Autoradiograph of RNA transcripts from transcription reactions represented in the bar graph in $C$. an extension of protection downstream of the TATA box to approximately -5 . The upstream footprint was reduced to approximately -33 (Fig. 7C, lane 3). In addition, DNase I hypersensitive sites were observed at residues -19 and -20 . Further increase in the amount of Drl-DRAPl complex added to the footprinting reaction did not alter the area protected from cleavage around the TATA motif but resulted in the enhancement and production of a series of sites that were hypersensitive to DNase I cleavage (lane 4). These hypersensitive sites mapped to the upstream border of the TBP footprint at residues -32 and -33 as well as to residues downstream of the TATA motif located at $-3,-14,-15,-16,-19$, and -20 . These results strongly suggest that the Dr1DRAPl complex not only binds to TBP and precludes the entry of TFIIA and/or TFIIB but also alters the structure of the TBP-TATA motif complex (see discussion).

DRAP1 is specifically immunodetected in differentiated nondividing cells

Northern blot analyses of DRAP1 RNA derived from different human tissues revealed a predominant RNA species of $\sim 1.1 \mathrm{~kb}$. This RNA was expressed at different levels in all tissues analyzed, with apparent higher levels of expression in tissues with a low mitotic index (Fig. 7A). Drl was also expressed at different levels in all tissues analyzed (Fig. 7A). To explore further whether the Northern blot results were of any significance, we studied DRAPl and Drl in the brain of a developing rat. The brain was chosen because it contains both actively dividing and highly differentiated cells.

At day 15 before birth (E15), the cerebral wall is comprised of several zones. Mitotically active cells are confined to the ventricular and emerging subventricular zones, whereas the subplate and cortical plate are comprised of postmitotic neurons in $G_{0}$. Mitosis does not occur in either of the latter zones (Hicks and D'Amato 1968; Levitt 1994). The intermediate zone contains mostly postmitotic, migratory neurons at this age. The spatial segregation of cell populations in the developing cerebral wall permits the identification of proteins that are present in cells that are mitotically active or have completed their terminal division. It is clear, in alternate sections stained with DRAP1, Drl, and TBP antibodies, that there is differential immunodetection of the proteins in distinct cell populations (Fig. 8B). The ventricular/subventricular zones are devoid of DRAPl staining (Fig. 8Ba), although most cells in this proliferative region are immunoreactive for both Drl (Fig. $8 \mathrm{Bb}$ ) and TBP (Fig. $8 \mathrm{Bc}$. In marked contrast to the other zones of the cerebral wall at E15, intense DRAP1 immunoreactivity is evident in postmitotic neurons that settle in the subplate/cortical plate (Fig. 8Ba); these neurons once again exhibit Drl immunoreactivity and continue to express TBP. The absence of DRAPl staining in the intermediate zone suggests that this protein is not expressed immediately after cells complete their terminal division, but rather its appearance is delayed temporally, linking ex- 
Figure 7. Drl and DRAPl preclude the interaction of TFIIA and/or TFIIB with TBP on the AdMLP. Binding reactions were performed as described in Materials and methods. (A) Titration of $\mathrm{rDrl}$ and rDRAP1 over TBP-TFIIA complexes. The amounts of rDRAPl and rDrl are indicated at the top. The TA (DNA-TBPTFIIA) complex is indicated at left. The complex migrating directly above the TA complex (lane 2), represents the TA-rDrl complex described previously (Inostroza et al. 1992). (B) Analysis of DRAPl mutations on DRAP1-Dr1-TBP complex formation in the presence of TFIIA. The amounts of $\mathrm{rDrl}$ and rDRAPl titrated in the presence of TBP are indicated at the top. The TA (DNA-TBP-TFIIA) complex is indicated at left. (C) Titration of $\mathrm{rDr} 1$ and rDRAPl in the presence of TBP and the AdMLP promoter. The amounts of wild-type DRAPl proteins titrated in the presence of a fixed amount of $\mathrm{rDrl} / 10 \mathrm{ng}$, lanes 2-7) over the TBP-TFIIA complexes are indicated at the top. Complex 1 is the fastest migrating band. (D) DNase I footprinting analysis of the DRAPI-DrI-TBP complex binding to AdMLP sequences. Human TBP (10 ng, lane 2) and TBP plus two different amounts of the DRAPI-Drl complex (10 ng, lane 3; $30 \mathrm{ng}$, lane 4) were added to DNase I footprinting reactions

A
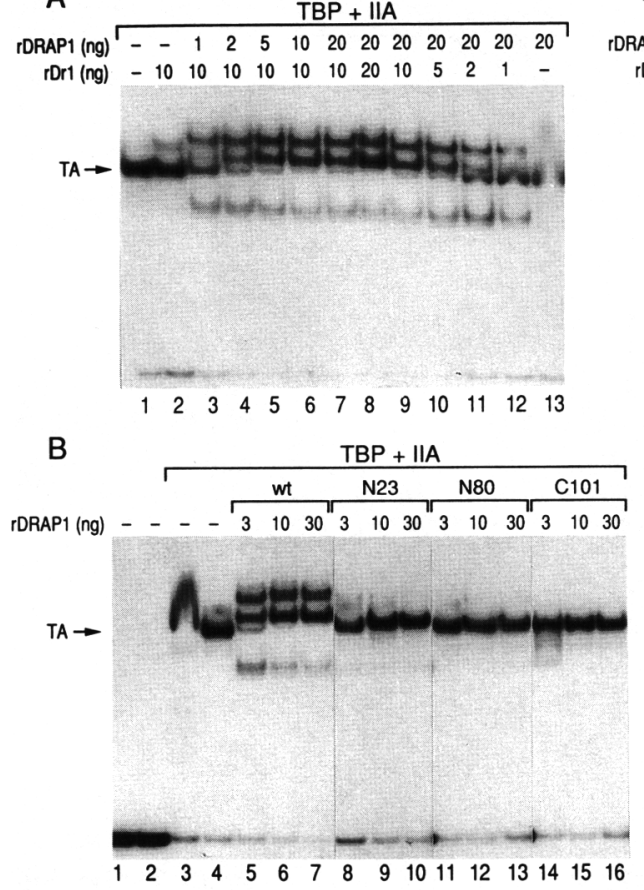



$\mathrm{D}$

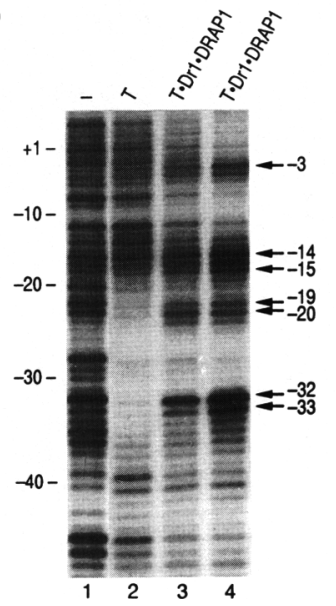
containing a DNA fragment that stretched the AdMLP $(-50$ to +10$)$. The samples were separated on $6 \%$ polyacrylamide-urea gels. $(-)$ The control pattern of DNase I digestion obtained in the absence of protein. The relative positions of regions containing hypersensitive sites from DNase I are indicated by arrows at right. Native Drl is used in footprinting analysis to assure stoichiometric amounts of both Drl and DRAP1.

pression to the completion of migration. The specific immunolocalization of DRAPl in postmitotic neuronal populations also was seen in other, more differentiated brain regions where neurogenesis was almost complete (data not shown). The pattern of immunostaining highlights differential regulation of each of the three proteins and indicates that the tripartite complex, which is the most active in terms of repression, is likely to exist only in the postmitotic, highly differentiated neuronal population.

\section{Discussion}

In our present studies we have identified a Drl-associated protein referred to as DRAPl that enhances Drl repression of transcription. The combination of both recombinant factors reconstitutes levels of repression comparable to that of native Drl. We observed that the levels of recombinant Drl required to inhibit transcription were significantly higher, relative to the levels of native Drl needed to obtain the same effect. This difference in activity can now be attributed to the presence of a corepressor contained in native Dr1, DRAP1. Two different cDNA clones representing DRAPl were isolated. One clone was isolated from a liver cell library that differed by the addition of an internal 7 amino acids from the HeLa cell library-derived cDNA. Also, two different Drl-containing complexes were isolated by immunoaffinity chromatography derived from the $0.5 \mathrm{M}$ and $1.0 \mathrm{M}$ phosphocellulose fractions. Western blot analysis of the immunoaffinity-purified complex from the $1.0 \mathrm{M}$ phosphocellulose column showed that the $30-\mathrm{kD}$ protein was immunologically related to DRAP1 distinguishing the existence of a modified form of DRAPl. Taken together, these results suggest that DRAPI may represent one protein in a family of related proteins.

The discovery of DRAPl has allowed a detailed uncierstanding of the mechanism underlying the ability of DrI to repress transcription. Despite the growing number of repressors that have been identified, no precise mechanism delineating repressor function at the promoter level has been elucidated. Previous studies have shown that at least two domains in Dr1 are important for repressor function: the TBP-binding domain, and the glutamine/alanine-rich motif (Yeung et al. 1994). In the present studies we have also shown that in addition to these two domains, the amino terminus containing the histone fold/HAP3 motif of Drl is required for its maximal activity. Without the amino terminus of Drl, the DRAP1 interaction is lost. Further examination of the importance of the histone fold/HAP homology region emerged from analysis of DRAP1 mutants. As expected, 


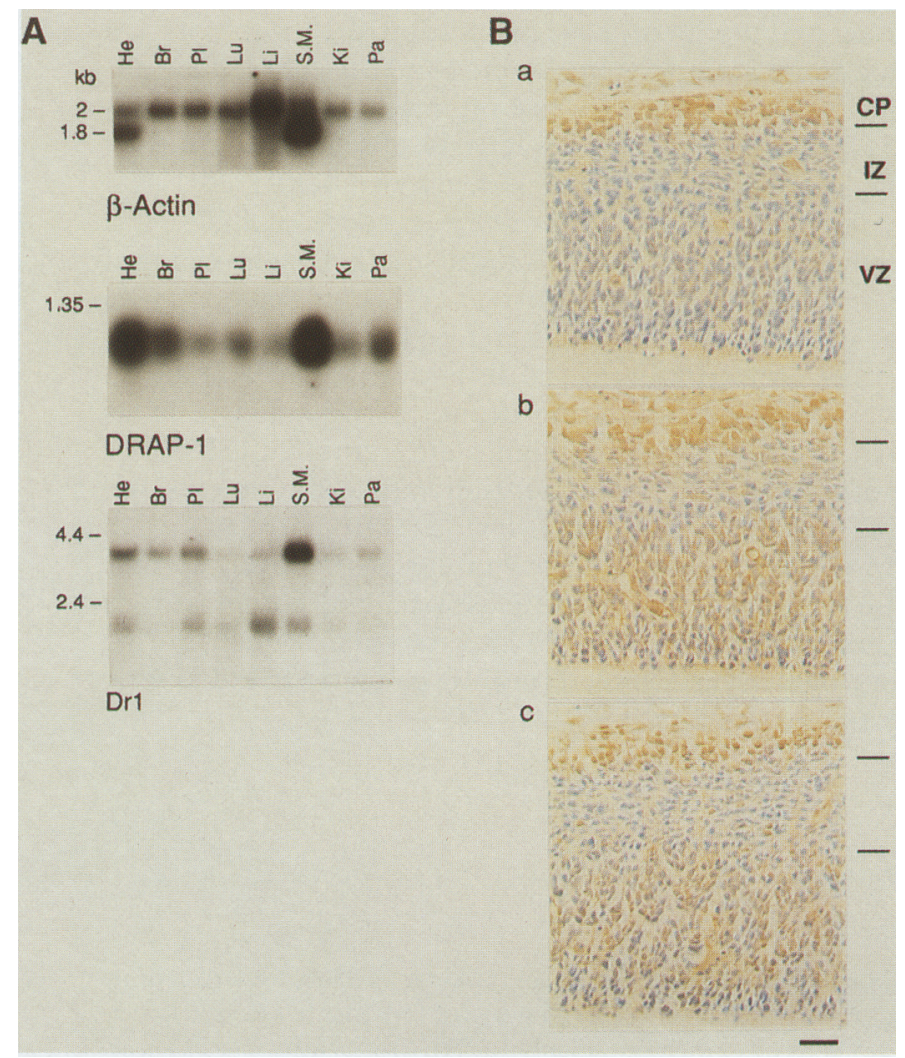

Figure 8. Immunodetection of DRAP1 during development in the brain. (A) Northern blot analysis of RNA complementary to Drl, DRAPl, and $\beta$-actin in human tissues. The entire coding sequences of Drl, DRAPl, and $\beta$-actin were labeled by random priming and used in the analysis. As described previously, two discrete RNA species of 1.5 and $3.4 \mathrm{~kb}$ hybridized to the Drl cDNA (Inostroza et al. 1992). One discrete RNA species of 1.1 $\mathrm{kb}$ hybridized to the DRAPl cDNA. Filters containing similar amounts of poly $\left(\mathrm{A}^{+}\right)$RNA obtained from different human tissues were obtained from Clontech and used as described in Materials and methods. Symbols representing the various tissues are as follows: $(\mathrm{He}) \mathrm{heart}(\mathrm{Br})$ brain; $_{\text {(Pl) placenta }}(\mathrm{Lu})$ lung; $(\mathrm{Li} \mid$ liver; (S.M.) smooth muscle; (Ki) kidney; (Pa) pancreas. (B) Photomicrographs of coronal sections through the cerebral wall at E15 illustrating the distribution of DRAPl $|A|$, Dr $1|B|$, and TBP $(C)$ following immunoperoxidase staining (brown). Sections are counterstained with $0.1 \%$ cresyl violet (blue). Intense DRAP1 immunoreactivity is observed only in cells situated in the cortical plate/subplate (CP). In contrast, Drl and TBP immunostaining is prominent in cells in the ventricular/subventricular zones (VZ) and cortical plate. Neurons migrating through the intermediate zone (IZ) do not express either DRAPl or Drl, but some continue to express TBP. Scale bar, $50 \mu \mathrm{m}$.

the histone fold/HAP5-containing amino terminus of DRAPl is also required for function. Without the histone fold/HAP5 region of DRAPl (N80), the physical association between Drl and DRAPl is lost. Moreover, the histone fold by itself, C101, does not interact with rDrl or repress transcription. We have shown that the Drl-DRAP1 complex can disrupt TA complexes. Unlike wild-type DRAP1, both N23 and C101 in combination with Drl do not dissociate TFIIA from interacting with TBP. These findings demonstrate that the interaction between DRAPl and Drl alone is not sufficient for activity but that the combination of proteins are required to dissociate TFIIA or TFIIB from preinitiation complexes for DRAPl to enhance Drl repression of transcription.

It has become evident that a number of transcriptional repressors from eukaryotes exist in multicomponent complexes. Similar to transcriptional activators, repressor complexes can be dissected into two integral components: a specific DNA-targeting constituent that is functionally inactive, unless in the presence of a second component mediating activity. This is exemplified by the Mad-Max transcriptional repression complex, which possesses a sequence-specific DNA-binding domain but can only repress transcription when associated with the mSin3 protein (Ayer et al. 1995; Schreiber-Agus 1995). Additionally, thyroid hormone receptor and the retinoid $\mathrm{X}$ receptor heterodimer, which binds to the thyroid hormone response element (TRE), has been shown to repress transcription in the absence of ligand, but only in the presence of a corepressor molecule known as N-CoR/ SMRT (Chen and Evans 1995; Horlein et al. 1995; Kurokawa et al. 1995). In yeast, the Cyc8 (Ssn6) and Tupl repressor complex has been shown to be recruited to promoters via sequence-specific DNA-binding prot zins (Tzamarias and Struhl 1995). For example, for repression of the SUC2 gene, Cyc8 (Ssn6) and Tup1 interact with the specific DNA-binding protein, Mig 1 (Tzamarias and Struhl 1995). Cyc8 (Ssn6) and Tup1 can also repress the transcription of the a-specific genes by complexing with the DNA-bound MCMI and $\alpha 2$ heterodimer (Keleher et al. 1992). In the Ssn6-Tupl complex, only Tupl contains an identifiable repressor domain (Tzamarias and Struhl 1994). In all of these cases, the repressor domain is confined to one component of the repressor complex. This recruitment-based mechanism is similar for DRAPl and Drl in that Drl and DRAP1 interact with the promoter via the DNA-binding protein, TBP, and that only Drl contains the repressor domain. It is this interaction that characterizes Drl and DRAP1 as general repressors of transcription and sets them apart from other repressor complexes.

The Drl-TBP interaction is considered to compete with the ability of TFIIA and TFIIB to bind to TFIID and form a functional preinitiation complex (Inostroza et al. 1992; Kim et al. 1995|. Studies using point mutations in the basic repeat region of TBP have suggested that both Drl and TFIIA compete directly for binding to this region (Kim et al. 1995). In the same study Drl was shown not to compete directly for the TFIIB-binding site on TBP, suggesting that the interaction of Drl with TBP results in a conformational change that disrupts the TFIIB-TFIID interaction. In our DNase I footprint analysis of the TBP-DNA complex, in the presence of Dr1DRAPl, we observed at least four hypersensitive sites. These likely arose from changes in DNA conformation. This observation is congruent with the histone fold motif observed in both Drl and DRAPl. Specifically, proteins containing this motif engage in either protein- 
protein interactions or protein-DNA interactions (Baxevanis 1995). High-resolution hydroxyl radical footprint analysis has shown that TFIIB requires at least $7 \mathrm{bp}$ on either side of the TATA box to form a stable TFIIB-TBPDNA complex (Lee and Hahn 1995). The structure of the TFIIB-TBP-DNA complex was subsequently confirmed by $\mathrm{x}$-ray crystallography and by alanine scanning, demonstrating that core TFIB interacts with the carboxyterminal stirrup of TBP and contacts the backbone of the core promoter upstream and downstream of the TATA element (Nikolov et al. 1995; Tang et al. 1996). Interestingly, the hypersensitive regions that occur as a result of the binding of the DRAP1/Drl to the TBP-DNA complex coincide with the regions required for the production of a stable TFIIB-TBP-DNA complex. The ability of Drl and DRAP1 to form a stable repressor complex may also account for its action in blocking RNA polymerase III transcription. In this system Drl inhibits the ability of B-related factor, which contains significant homology to TFIIB, to interact with TBP and recruit RNA polymerase III (White et al. 1994).

Northern blot analysis demonstrated varied expression of DRAP1 in different tissues. Interestingly, the differences in expression appear to correlate with the overall mitotic activity of the cells. For example, DRAP1 expression was higher in tissues containing a low percentage of actively dividing cells, (i.e., heart, skeletal muscle). Because it is difficult to draw general conclusions about DRAPl expression from tissues containing mixed populations of actively dividing, differentiated, or growth-arrested cells, immunohistochemical analyses were undertaken. The developing rat brain was chosen for our experiments as it is known to contain rapidly dividing populations of progenitor cells, as well as postmitotic, migrating, and differentiating neurons. These cell populations are segregated into different compartments of the developing cerebral cortex. Our analysis revealed striking differences in the immunoreactivity of DRAP1, Dr1, and TBP. Drl and TBP are expressed in the proliferative ventricular/subventricular zones in the developing brain. All three proteins were found only in the cortical plate that is restricted to differentiating postmitotic neurons. The robust colocalization to the same cell population suggests that DRAPl may be required for enhanced repressor activity when neurons enter $G_{o}$ and begin to express phenotype-specific gene products. The immunolocalization experiments also reveal that DRAP1 protein is not detected until the postmitotic neurons reach the cortical plate and cease migrating. Despite the fact that Dr1/DRAPl exist as general repressors in vitro, the ability of only certain specific classes of activators to overcome the repression mediated by DrlDRAPl (Yeung et al. 1994) may be important in the expression of genes required in the differentiation process. Therefore, given to dramatic changes in patterns of gene expression that occur subsequently in these neurons, DRAPl expression may facilitate the maintenance of a differentiated state by silencing specific genes.

In summary, we have defined a novel class of a corepressor molecule, DRAP1, that together with the TBP- associated repressor, Drl, can inhibit the formation of a functional preinitiation complex and the subsequent initiation of transcription. The interaction of DRAP1 with Drl has revealed that the activity of Drl as a repressor can be modulated. In the absence of DRAP1, Dr1 is a weak repressor, whereas in the presence of DRAP1, a strong repressor complex is formed. We have shown that Drl is expressed in neural stem cells that apparently do not express DRAP1, and therefore Drl-mediated repression of transcription in the absence of DRAP1 in an actively dividing population cannot be expected to be as high as in nondividing, highly differentiated cells. The ability of DRAPl to differentially affect the overall process of repression through Drl directly correlates with the coexpression of these proteins in mature neurons. The significance of DRAPl as a general corepressor of transcription may prove to have profound effects during development and for determining cell fates in eukaryotic systems.

\section{Materials and methods}

\section{Purification of DRAP1}

p28 was purified from HeLa cell nuclear extracts by virtue of its tight association with Drl. Therefore, its purification was performed as described previously for Drl from the $0.5 \mathrm{M} \mathrm{P} 11$ fraction (Inostroza et al. 1992), except that in the last step of purification following a gel filtration step (Superdex 200 column), a Drl immunoaffinity column was employed. Drl found in the $1.0 \mathrm{M}$ Pll fraction was purified similarly, except the third step of purification (DEAE-5PW) was not performed. Affinity-purified Drl antibodies ( $2 \mathrm{mg}$ ) were coupled to $1 \mathrm{ml}$ of recombinant protein A-agarose (Repligen) using $20 \mathrm{~mm}$ dimethylpimelimidate as described (Harlow and Lane 1988). The resin was incubated for $90 \mathrm{~min}$ at $4^{\circ} \mathrm{C}$ with the $\mathrm{S} 200$ fraction $(0.5 \mathrm{ml}, 0.1$ $\mathrm{mg} / \mathrm{ml}$ diluted in two volumes of buffer containing $20 \mathrm{~mm}$ Tris- $\mathrm{HCl}$, (pH 7.9), $0.2 \mathrm{~mm}$ EDTA, $50 \mathrm{~mm} \mathrm{NaF}, 100 \mu \mathrm{M} \mathrm{NaVO}$, $100 \mathrm{mM} \mathrm{KCl}, 1 \% \mathrm{NP}-40$ and $1 \mathrm{mM}$ PMSF. Immunoadsorbed complexes were then washed with $10 \mathrm{ml}$ of this buffer and eluted with $0.1 \mathrm{M}$ glycine- $\mathrm{HCl}(\mathrm{pH} 2.6)$, or in $\mathrm{BC} 100$ containing $0.05 \%$ Sarkosyl to separate $\mathrm{p} 28$ from $\mathrm{Drl}$ and remaining bound Drl eluted with $0.1 \mathrm{M}$ glycine- $\mathrm{HCl}(\mathrm{pH} 2.6)$. Drl eluates derived from the immunoaffinity column steps were concentrated on a micro Mono S column. Fractions were analyzed by SDS-PAGE followed by Western blot analysis using affinity-purified Drl antibodies and by silver staining.

\section{Amino acid sequencing of DRAPS}

Ponceau S-stained bands were excised and processed for "internal" sequencing as described (Tempst et al. 1990), with modifications (Erdjument-Bromage et al. 1994). Briefly, in-situ proteolytic cleavage was done using $0.5 \mu \mathrm{g}$ of trypsin (Promega, Madison, WI) in $25 \mu \mathrm{l}$ of $100 \mathrm{~mm} \mathrm{NH} \mathrm{NCO}_{3}$ (supplemented with $0.3 \%$ Tween 80 ) at $37^{\circ} \mathrm{C}$ for $3 \mathrm{hr}$. The resulting peptide mixture was reduced and S-alkylated with, respectively, $0.1 \%$ $\beta$-mercaptoethanol (Bio-Rad, Richmond, CA) and 0.3\% 4-vinyl pyridine (Aldrich, Milwaukee, WI), and fractionated by reversephase HPLC. An enzyme blank was done on an equally sized strip of nitrocellulose. HPLC solvents and system configuration 
were as described (Elicone et al. 1994), except that a $2.1 \mathrm{~mm}$ Vydac C4 (214TP54) column (The Separations Group, Hesperia, CA) was used with gradient elution at a flow rate of $100 \mu \mathrm{l} / \mathrm{min}$. Fractions were collected by hand, kept on ice for the duration of the run, and stored at $-70^{\circ} \mathrm{C}$ before analysis. Chemical sequencing of selected peptides was done using a model $477 \mathrm{~A}$ instrument (Applied Biosystems, Foster City, CA) with "online" analysis (120A HPLC system with $2.1 \times 220-\mathrm{mm} \mathrm{PTH} \mathrm{C18}$ column; Applied Biosystems). Instruments and procedures were optimized for femtomole level phenylhydantoin amino acid analysis as described (Erdjumant-Bromage et al. 1994; Tempst et al. 1994).

\section{Expression of DRAP1 in E. coli}

A set of primers were generated bearing the amino- and carboxyterminal ends of DRAPl-coding sequence that were flanked by NdeI and BamHI sites (amino terminus, 5'-dGGCTGTAACATATGGAATTCCGGATCAAG- ${ }^{\prime}$; carboxyl terminus, $5^{\prime}$ TCTTCTGGATCCTCAGGTGCTGAGGGGCCC-3'; the boldface sequences represent both the NdeI and BamHI sites|. These primers were used in PCR reactions to generate a product containing coding sequences flanked by these two sites. The PCR product was digested with $\mathrm{NdeI}$ and $\mathrm{BamHI}$ and cloned in-frame with a amino-histidine tag in the plasmid vector $\mathrm{pET} 15 \mathrm{~b}$ (Novagen). E. coli strain BL21 (DE3, Novagen) containing DRAPl was grown in Luria-Bertani medium supplemented with ampicillin $(100 \mu \mathrm{g} / \mathrm{ml})$ at $37^{\circ} \mathrm{C}$. Cells were grown to 0.6 at $\mathrm{OD}_{600}$ and then induced with $1 \mathrm{~mm}$ isopropylthiogalactoside (IPTG). After $3 \mathrm{hr}$, cells were pelleted and the histidine fusion proteins were purified as described by Hoffmann and Roeder (1991).

Construction of DRAP1 amino- and carboxy-terminal deletion mutants

For amino-terminal deletion mutants, the following oligonucleotides were designed as amino-terminal primers for PCR: (N23) 5'-dGACGGGATCCCATATGGTCATCATCTCCCGGGCG-3'; 5'-dTCCGGGATCCCATATGGACATGCAGGGGGACGGG-3' (N80). For carboxy-terminal deletion mutants, the following oligonucleotides were designed as C-terminal primers for PCR: 5'-dTGGCGA TCCTCTA GAGTTG TGA TGT CTCCT CTTC-3' (C144), 5'-dCCCGGGATCCTCTAGAGCTTCCGGCCCCTGCGGGC-3' (C101). The above primers were used together with amino oligonucleotide 5'-dGGCTGTAAGGATCCCATATGGAATTCCGGATCAAG-3' to amplify DNA fragments from p28 cDNA cloned in pFlag-2 (Kodak, Inc.) (the boldface sequences represent the $B a m H I$ and $E c o R I$ sites respectively). After restriction digestion with EcoRI and $B a m H I$ the fragments were inserted into a pFlag-2 vector (Kodak, Inc). All mutations were verified by DNA sequencing.

\section{Histone fold motif sequence analysis}

Using the multiple alignment of the histone fold sequences (Baxevanis et al. 1995), we queried a modified SWISSPROT data base of protein sequences for possible matches to the histone fold. The data base was constructed from the data residing in the data base on August 4, 1995, to which was added the DRAPl, Hap5p, and CBF-C sequences. This data base contained 53,122 sequences and consisted of 19,162,929 total letters. We used the motif search tool (MOST) (Tatusov et al. 1994) to search this data base. An $r$-value $<0.001$ was used as a threshold to ensure that only highly probable events are identified. The $r$-value is the ratio of the expected number of sequence segments with a given score, to the observed number.

\section{Protein-binding assays by surface plasmon resonance}

Protein interactions detected by surface plasmon resonance were performed using a BIAcore instrument from Pharmacia Biosensor $A B$. rDrl $(0.6 \mu \mathrm{g})$ served as the surface-immobilized target protein and was dialyzed into PBS, coupled to a BLAcore sensor chip CM5 using $N$-hydroxysuccinimide (NHS), and $N$-ethyl- $N^{\prime}$-(3-diethylaminopropyl)carbodimide (EDC), and $1 \mathrm{M}$ ethanolamine hydrochloride $(\mathrm{pH} 8.5)$. Sensor chips containing between 200 and 500 resonance units (RU) of $\mathrm{rDr}$ l were used for experiments. Immobilizations were performed automatically in the instrument. HBS buffer (10 mM HEPES with $0.15 \mathrm{M} \mathrm{NaCl}$, $3.4 \mathrm{~mm}$ EDTA, and $0.05 \%$ surfactant $\mathrm{P} 20$ at $\mathrm{pH} 7.4$ ) was used as running buffer for injection of proteins. Different amounts of either mutant (10 ng) or wild-type DRAPl (1.6-10 ng) were injected in a total volume of $30 \mu \mathrm{l}$ in HBS buffer at $5 \mu \mathrm{l} / \mathrm{min}$ continuous flow. After each protein injection, two consecutive washes of Sarkosyl $(0.05 \%)$ in HBS were injected in $10 \mu l$ at 5 $\mu \mathrm{l} / \mathrm{min}$ continuous flow to dissociate proteins interacting with surface bound rDrl. All experiments were performed at room temperature.

\section{Protein-binding assays using GST fusion proteins}

The GST fusion proteins were expressed in E. coli. Approximately $20 \mu \mathrm{l}$ of glutathione-agarose beads containing $1 \mu \mathrm{g}$ of the fusion protein was incubated at $4^{\circ} \mathrm{C}$ in $0.5 \mathrm{ml}$ of buffer containing $20 \mathrm{mM}$ Tris- $\mathrm{HCl}$ buffer, $(\mathrm{pH} 7.5), 0.1 \mathrm{M} \mathrm{NaCl}, 0.2 \mathrm{mM}$ EDTA, $1 \mathrm{mM}$ DTT, $1 \mathrm{mM}$ PMSF, and $0.2 \%$ NP-40. Equal amounts of either bacterial lysate or in vitro-translated protein was added and binding was allowed to proceed for $1 \mathrm{hr}$. The beads were washed four times with the same buffer with $0.4 \%$ NP-40, and the bound proteins eluted with $30 \mu$ l of SDS-PAGE loading buffer and resolved by electrophoresis. In vitro-translated proteins were visualized by fluorography. Bacterially produced proteins were visualized by Western blotting.

\section{Immunocytochemistry}

Immunolocalization of DRAP1, Dr1, and TBP were performed using a modification of a previously published protocol (Ferri and Levitt 1993). Brains were dissected from E15 Holtzmann albino rats and immersion fixed in $4 \%$ paraformaldehyde $1 \mathrm{pH}$ 6.5 ) for $2 \mathrm{hr}$ and in $4 \%$ paraformaldehyde $(\mathrm{pH} 9$ ) overnight at $4^{\circ} \mathrm{C}$. Following sucrose cryoprotection, the brains were frozen, serially sectioned in the coronal plane at $14 \mu \mathrm{M}$ and collected in four series on chromium potassium sulfate alum-gelatin/polyL-lysine-coated glass slides. Adjacent sections were processed for immunolocalization of each protein. Sections first were treated with $0.3 \%$ hydrogen peroxide in methanol for $30 \mathrm{~min}$ to quench endogenous peroxidase activity, followed by blocking in Blotto $4 \%$ Carnation dried milk in PBS), containing $0.3 \%$ triton $\mathrm{X}-100$. Primary antibody incubation (1:4000 dilution) was overnight at room temperature, followed by extensive washing and standard biotin-streptavidin-HRP (Jackson Immuno Research Products/ reaction. For DRAPl and Drl staining, affinity-purified rabbit polyclonal antibodies were used $(0.2 \mathrm{mg} / \mathrm{ml})$. For TBP staining, monoclonal antibodies, SL39 $(0.2 \mathrm{mg} / \mathrm{ml})$ (gift of N. Hernandez, Cold Spring Harbor Laboratory, Cold Spring Harbor, NY) were used. Sections were photographed, and counterstained with $0.1 \%$ cresyl violet and rephotographed to aid in the identification of the brain regions containing specific immunoreactivity. The terminology used to describe developing zones 
of the cerebral wall is according to the Boulder Committee (1970).

\section{Gel shift assays}

Proteins and the radiolabeled AdMLP $\mid-40$ to $+13, \sim 5000 \mathrm{cpm}$, $0.1-1 \mathrm{ng}$ / were incubated in the presence of $100 \mu \mathrm{g} / \mathrm{ml}$ of BSA for $30-45 \mathrm{~min}$ at $30^{\circ} \mathrm{C}$ in a $20 \mu \mathrm{l}$ volume as described previously (Maldonado et al. 1990). The reaction products were analyzed on $6 \%$ polyacrylamide gels containing $25 \mathrm{~mm}$ TRIS /pH 8.31 190 $\mathrm{mm}$ glycine, $5 \mathrm{~mm}$ magnesium acetate, $2.5 \%$ (vol/vol) glycerol, and $0.5 \mathrm{~mm}$ DTT in running buffer containing $25 \mathrm{~mm}$ TRIS / $\mathrm{pH}$ 8.3) $190 \mathrm{~mm}$ glycine, and $5 \mathrm{~mm}$ magnesium acetate as described by Auble and Hahn (1993).

\section{Other methods}

Transcription factors were purified as described by Flores et al. (1992). RNA PII was purified as described by Lu et al. (1991). Transcription assays and DNase I footprinting analysis were performed as described by Maldonado et al. (1990). Northern blot analysis was performed as described by Ha et al. (1991). Polyclonal antibodies were produced as described previously for Drl by Inostroza et al. (1992).

\section{Acknowledgments}

We thank Drs. George Orphanides and Ronny Drapkin for stimulating discussions and reading the manuscript. This work was supported by a grant from the National Institutes of Health (GM48518) and Howard Hughes Medical Institute to D.R. This work was also supported, in part, by the Irma T. Hirschl Foundation and National Science Foundation grant BIR-9420123 (to P.T.), and National Cancer Institute Cancer Core grant 5P30 CA08748-29 to the Sloan-Kettering Microchemistry Facility. We thank Mary Lui for assistance with protein sequencing. We also thank Dr. Osvaldo Flores for the gift of CMV-IE2 protein and the AdMLP containing CRE.

The publication costs of this article were defrayed in part by payment of page charges. This article must therefore be hereby marked "advertisement" in accordance with 18 USC section 1734 solely to indicate this fact.

\section{References}

Abmayr, S.M., J.L. Workman, and R.G. Roeder. 1988. The pseudorabies immediate early protein stimulates in vitro transcription by facilitating TFIID: Promoter interaction. Genes \& Dev. 2: 542-553.

Auble, D.T. and S. Hahn. 1993. An ATP-dependent inhibitor of TBP binding to DNA. Genes \& Dev. 7: 844-856.

Ayer, D.E., Q.A. Lawerence, and R.N. Eisenman. 1995. Madmax transcriptional repression is mediated by ternary complex formation with mammalian homologs of yeast repressor sin 3. Cell 80: 767-776.

Baniahmad, A., I. Ha, D. Reinberg, S. Tsai, M.J. Tsai, and B.W. O'Malley. 1993. Interaction of human thyroid hormone receptor beta with transcription factor TFIIB may mediate target gene derepression and activation by thyroid hormone. Proc. Natl. Acad. Sci. 90: 8832-8836.

Baxevanis, A.D., G. Arents, E.N. Moundrianakis, and D. Landsman. 1995. A variety of DNA-binding and multimeric proteins contain the histone fold motif. Nucleic Acids Res. 23: $2685-2691$.

Boulder Committee. 1970. Embryonic vertebrate central ner- vous system: Revised terminology. Anat. Rec. 166: 257-261.

Buratowski, S., S. Hahn, L. Guarente, and P. Sharp. 1989. Five intermediate complexes in transcription initiation by RNA polymerase II. Cell 56: 549-561.

Chan, Y-L., V. Paz, I. Olevera, and I.G. Wool. 1993. The primary structure of rat ribosomal protein S9. Biochim. Biophys. Acta. 193: 106-112.

Chen, I.D. and R.M. Evans. 1995. A transcriptional corepressor that interacts with nuclear hormone receptors. Nature 377: 454-457.

Chong, A.A., J. Tapia-Ramirez, S. Kim. J.J. Toledo-Aral, Y. Zheng, M.C. Boutros, Y.M. Altshuller, M.A. Frohman, S.D. Kraner, and G. Mandel. 1995. REST: A mammalian silencer protein that restricts sodium channel gene expression to neurons. Cell 80: 949-957.

Choy, B. and M. Green. 1993. Eukaryotic activators function during multiple steps of preinitiation complex assembly. Nature 366: 531-536.

Cortes, P., O. Flores, and D. Reinberg. 1992. Factors involved in specific transcription by mammalian RNA polymerase II: Purification and analysis of transcription factor IIA and identification of transcription factor IIJ. Mol. Cell. Biol. 12: 413421.

Dynlacht, B.D., T. Hoey, and R. Tiian. 1991. Isolation of coactivators associated with the TATA-binding protein that mediate transcriptional activation. Cell 66: 563-576.

Elicone, C., M. Lui, S. Geromanos, H. Erdjument-Bromae, and P. Tempst. 1994. Microbe reversed-phase high-performance liquid chromatographic purification of peptides for combined chemical sequencing/laser-desorption mass spectrometric analysis. J. Chromatogr. 676: 121-137.

Elledge, S.J., Z. Zhou, J.B. Allen, and T. Navas. 1993. DNA damage and cell cycle reglation of ribonucleotide reductase. BioEssays 15: 333-339.

Erdjument-Bromage, H., M. Lui, D.M. Sabatini, S.H. Snyder, and P. Tempst. 1994. High-sensitivity sequencing of large proteins: Partial structure of the rapamucin-FKB12 target. Prot. Sci. 3: 2435-2446.

Ferri, R.T. and P. Levitt. 1993. Cerebral cortical progenitors are fated to produce region-specific neuronal populations. Cereb. Cortex 3: 187-198.

Flores, O., I. Ha, and D. Reinberg. 1990. Factors involved in specific transcription by mammalian RNA polymerase II. Purification and subunit composition of transcription factor IIF. /. Biol. Chem. 265: 5629-5634.

Flores, O., H. Lu, and D. Reinberg. 1992. Factors involved in specific transcription by mammalian RNA polymerase II. Identification and characterization of factor IIH. $l$. Biol. Chem. 267: 2786-2793.

Gill, G. and R. Tiian. 1992. Eukaryotic coactivators associated with the TATA box binding protein. Curr. Opin. Genet. Dev. 2: 236-242.

Ha, 1., W.S. Lane, and D. Reinberg. 1991. Cloning of a human gene encoding the general transcription initiation factor IIB. Nature 352: 689-695.

Harlow, E. and D. Lane. 1988. Antibodies: A laboratory manual. Cold Spring Harbor Laboratory Press, Cold Spring Harbor, NY.

Herschbach, B.M. and A.D. Johnson. 1993. Transcriptional repression in eukaryotes. Annu. Rev. Cell. Biol. 9: 479-509.

Hicks, S.P. and C.J. D'Amato. 1968. Cell migrations to the isocortex in the rat. Anat. Rec. 160: 619-634.

Hoffmann, A. and R.G. Roeder. 1991. Purification of his-tagged proteins in non-denaturing conditions suggests a convenient method for protein interaction studies. Nucleic Acids Res. 19: 6337-6338. 
Hoffman, A., E. Sinn, T. Yamamoto, J. Wang, A. Roy, M. Horikoshi, and R.G. Roeder. 1990. Highly conserved core domain and unique $\mathrm{N}$ terminus with presumptive regulatory motifs in a human TATA factor (TFIID). Nature 346: 387-390.

Horlein, A.J., A.M. Naar, T. Heinzel, J. Torchia, B. Gloss, R. Kurokawa, A. Ryan, Y. Kamel, M. Soderstrom, C. Glass, and M.G. Rosenfeld. 1995. Ligand-independent repression by the thyroid hormone receptor mediated by a nuclear receptor co-repressor. Nature 377: 397-404.

Inostroza, J.A., F.H. Mermelstein, I. Ha, W.S. Lane, and D. Reinberg. 1992. Drl, a TATA-binding protein-associated phosphoprotein and inhibitor of class II gene transcription. Cell 70: $477-489$.

Johnson, A.D. 1995. The price of repression. Cell 81: 655-658.

Johnson, F.B. and M.A. Krasnow. 1992. Differential regulation of transcription preinitiation complex assembly by activator and repressor homeo domain proteins. Genes \& Dev. 6: $2177-2189$

Kao, C.C., P.M. Lieberman, M.C. Schmidt, Q. Zhou, R. Pei, and A.J. Berk. 1990. Cloning of a transcriptionally active human TATA binding factor. Science 248: 1646-1650.

Keleher, C.A., J. Redd, M. Schultz, M. Carlson, and A.D. Johnson. 1992. Ssn6-Tupl is a general repressor of transcription yeast. Cell 68: 709-719.

Kim, T.K., Y. Zhao, H. Ge, R. Bernstein, and R.G. Roeder. 1995. TATA-binding protein residues implicated in a functional interplay between negative cofactor NC2 (Drl) and general factors TFIIA and TFIIB. J. Biol. Chem. 270: 10976-10981.

Koleske, A.J. and R.A. Young. 1995. An RNA polymerase II holoenzyme responsive to activators. Nature 368: 466-469.

Kraus, V.B., J.A. Inostroza, K. Yeung, D. Reinberg, and J.R. Nevins. 1994. Interaction of the Drl inhibitory factor with the TATA binding protein is disrupted by adenovirus ElA. Proc. Natl. Acad. Sci. 91: 6279-6282.

Kurokawa, R., M. Soderstrom, A. Horlein, S. Halachml, M. Brown, M.G. Rosenfeld, and C.K. Glass. 1995. Polarity-specific activities of retinoic acid receptors determined by a corepressor. Nature 377: 451-454.

Lee, G., J. Wu, P. Luu, P. Gazal, and O. Flores. 1996. Inhibition of the association of RNA polymerase II with the preinitiation complex by a viral transcriptional repressor. Proc. Natl. Acad. Sci. 93: 2570-2575.

Lee, S. and S. Hahn. 1995. Model for binding of transcription factor TFIIB to the TBP-DNA complex. Nature 376: 609612.

Levitt, P. 1944. Experimental approaches that reveal principles of cerebra cortical development. In The cognitive neurosciences (ed. M.S. Gazzaniga), pp. 147-163. MIT Press, New York, NY.

Lehming, N., D. Thanos, J.M. Brickmean, J. Ma, T. Maniatis, and M. Ptashne. 1994. An HMG-like protein that can switch a transcriptional activator to a repressor. Cell 371: 175-179.

Lieberman, P.M. and A.J. Berk. 1994. A mechanism for TAFs in transcriptional activation: Activation domain enhancement of TFIID-TFIIA-promoter DNA complex formation. Genes \& Dev. 8: 995-1006.

Liu, B., W. Hermisten, and M.F. Stinski. 1991. A cis-acting element in the major immediate-early (IE) promoter of human cytomegalovirus is required for negative regulation by IE2. $J$. Virol. 65: 897-903.

Lu, H., O. Flores, R. Weinmann, and D. Reinberg. 1991. The nonphosphorylated form of RNA polymerase II preferentially associates with the preinitiation complex. Proc. Natl. Acad. Sci. 88: 10004-10008.

$\mathrm{Ma}$, D., H. Watanabe, F. Mermelstein, A. Admon, K. Oguri, X. Sun, T. Wada, T. Imai, D. Shiroya, D. Reinberg, and H. Honda.
1993. Isolation of a cDNA encoding the largest subunit of TFIIA reveals functions important for activated transcription. Genes \& Dev. 7: 2246-2257.

Maheswaran, S., S. Park, A. Bernard, J.F. Morris, F.J. Rauscher, D.E. Hill, and D.A. Haber. 1993. Physical and functional interaction between $\mathrm{WTl}$ and p53 proteins. Proc. Natl. Acad. Sci. 90: 5100-5104.

Maldonado, E. and D. Reinberg. 1995. News on initiation and elongation of transcription by RNA polymerase II. Curr. Opin. Cell. Biol. 7: 352-361.

Maldonado, E., I. Ha, P. Cortes, L. Weis, and D. Reinberg. 1990 Factors involved in specific transcription by mammalian RNA polymerase II: Role of transcription factors IIA, IID, and IIB during formation of a transcription-competent complex. Mol. Cell. Biol. 10: 6335-6347.

Maxon, M.E., J.A. Goodrich, and R. Tjian. 1994. Transcription factor IIE binds preferentially to RNA polymerase IIa and recruits TFIIH: A model for promoter clearance. Genes \& Dev. 8: 515-524.

McNabb, D.S., Y. Xing, and L. Guarente. 1995. Cloning of yeast HAP5: A novel subunit of a heterotrimeric complex required for CCAAT binding. Genes and Dev. 9: 47-58.

Meisterernst, M. and R.G. Roeder. 1991. Family of proteins that interact with TFIID and regulate promoter activity. Cell 67: $557-567$

Meisterernst, M., A.L. Roy, H.M. Lieu, and R.G. Roeder. 1991. Activation of class II gene transcription by regulatory factors is potentiated by a novel activity. Cell 66: 981-993.

Mukai, Y., S. Harashima, Y. Oshima. 1991. AARl/TUP1 protein, with a structural similar to that of the $\beta$ subunit of $G$ proteins, is required for al- $\alpha 2$ and $\alpha 2$ repression in cell type control of Saccharomyces cerevisiae. Mol. Cell. Biol. 11: 3773-3779.

Nakajima, N., M. Horikoshi, and R.G. Roeder. 1988. Factors involved in specific transcription by mammalian RNA polymerase II: Purification, genetic specificity, and TATA boxpromoter interactions of TFIID. Mol. Cell. Biol. 8: 40284040.

Nikolov, D.B., H. Chen, E.D. Halay, A.A. Usheva, K. Hisatake, D.K. Lee, R.G. Roeder, and S.K. Burley. 1995. Crystal structure of a TFIIB-TBP-TATA element ternary complex. $\mathrm{Na}$ ture 377: 119-128.

Ossipow, V., J.-P. Tassan, E.A. Nigg, and U. Schibler. 1995. A mammalian RNA polymerase II holoenzyme containing all components requried for promoter-specific transcription initiation. Cell 83: 137-146.

Ozer, I., P.A. Moore, A.H. Bolden, A. Lee, C.A. Rosen, and P.M. Liberman. 1994. Molecular cloning of the small $(\gamma)$ subunit of human TFIIA reveals functions critical for activated transcription. Genes \& Dev. 8: 2324-2335.

Paroush, Z., R.L. Finley, T. Kidd, S.M. Wainwright, P.W. Ingham, R. Brent, and D. Ish-Horowicz. 1994. Groucho is required for Drosophila neurogenesis segmentation, and sex determination and interacts directly with hairy-related bHLH proteins. Cell 79: 805-815.

Peterson, M.G., N. Tanese, B.F. Pugh, and R. Tjian. 1990. Functional domains and upstream activation properties of cloned human TATA binding protein. Science 248: 1625-1630.

Pugh, B.F. and R. Tiian. 1991. Transcription from a TATA-less promoter requires a multisubunit TFIID complex. Genes \& Dev. 5: 1935-1945.

Roberts, S.G. and M.R. Green. 1995. Transcription. Dichotomous regulators. Nature 375: 105-106.

Sauer, F. and H. Jäckle. 1993. Dimerization and the control of transcription by Krüppel. Nature 364: 454-457.

Sauer, F., J.D. Fondell, Y. Ohkuma, R.G. Roeder, and H. Jäckle. 
1995. Control of transcription by Krüppel through interactions with TFIIB and TFIIE beta. Nature 375: 162-164.

Schreiber-Agus, N., L. Chin, K. Chen, R. Torres, G. Rao, P. Guida, A.I. Skoultchi, and R.A. DePinho. 1995. An aminoterminal domain of Mxil mediates anti-myc oncogenic activity and interacts with a homolog of the yeast transcriptional repressor SIN3. Cell 80: 777-786.

Schultz, J. and M. Carlson. 1987. Molecular analysis of SSN6, a gene functionally related to the SNF1 protein kinase of Saccharomyces cerevisiae. Mol. Cell Biol. 7: 3637-3645.

Seto, E., A. Usheva, G.P. Zambetti, J. Momand, N. Horikoshi, R. Weinmann, A.J. Levine, and T. Shenk. 1992. Wild-type p53 binds to the TATA-binding protein and represses transcription. Proc. Natl. Acad. Sci. 89: 12028-12032.

Sun, X., D. Ma, M. Sheldon, K. Yeung, and D. Reinberg. 1994. Reconstitution of human TFIIA activity from recombinant polypeptides: A role in TFIID-mediated transcription. Genes \& Dev. 8: 2336-2348.

Tang, H., X. Sun, D. Reinberg, and R.H. Ebright. 1996. Proteinprotein interactions in eukaryotic transcription initiation: Structure of the pre-initiation complex. Proc. Natl. Acad. Sci. 93: 1119-1124.

Tanese, N., B.F. Pugh, and R. Tjian. 1991. Coactivators for a proline-rich activator purified from the multisubunit human TFIID complex. Genes \& Dev. 5: 2212-2224.

Tatusov, R.L., S.F. Altschul, and E.V. Koonin. 1994. Detection of conserved segments in proteins: Iterative scanning of sequence databases with alignment blocks. Proc. Natl. Acad. Sci. 6: 12091-12095.

Tempst, P., A.J. Link, L.R. Riviere, M. Fleming, and C. Elicone. 1990. Internal sequence analysis of proteins separated on polyacrylamide gels at the submicrogram level: Improved methods, applications and gene cloning strategies. Electrophoresis 11: 537-533.

Tempst, P., S. Geromanos, C. Elicone, and H. Erdjument-Bromage. 1994. Improvements in microsequencer performance for low picomole sequence analysis. Methods: Companion Methods Enzymol. 6: 248-261.

Topol, J. and C.S. Parker. 1984. A Drosophila RNA polymerase II transcription factor contains a promoter-region-specific DNA binding activity. Cell 36: 357-369.

Trumbly, R.J. 1992. Glucose repression in the yeast Saccharomyces cerevisiae. Mol. Microbiol. 6: 15-21.

Tzamarias, D. and K. Struhl. 1994. Functional dissection of the yeast Cyc8-Tup1 transcriptional corepressor complex. $\mathrm{Na}$ ture 369: 758-761.

- 1995. Distinct TPR motifs of Cyc8 are involved in recruiting the Cyc8-Tupl corepressor complex to differentially regulated promoters. Genes \& Dev. 9: 821-831.

White, R.J., B.C.-E. Khoo, J.A. Inostroza, D. Reinberg, and S.P. Jackson. 1994. Differential regulation of RNA polymerase I, II, and III by the TBP-binding repressor, Drl. Science 266: $448-451$.

Yeung, K.C., J.A. Inostroza, F.H. Mermelstein, C. Kannabiran, and D. Reinberg. 1994. Structure-function analysis of the TBP-binding protein Drl reveals a mechanism for repression of class II gene transcription. Genes \& Dev. 8: 2097-2109.

Yokomori, K., M.P. Zeidler, J.L. Chen, C.P. Verrijzer, M. Mlodzik, and R. Tjian. 1994. Drosophila TFIIA directs cooperative DNA binding with TBP and mediates transcriptional activation. Genes \& Dev. 8: 2313-2323.

Zawel, L. and D. Reinberg. 1993. Initiation of transcription by RNA polymerase II: A multi-step process. Prog. Nucleic Acid Res. Mol. Biol. 44: 67-108.

. 1995. Common themes in assembly and function of eukaryotic transcription complexes. Annu. Rev. Biochem.
64: $533-561$.

Zhou, Q., P.M. Lieberman, T.G. Boeyer, and A.J. Berk. 1992. Holo-TFIID supports transcriptional stimulation by diverse activators and from TATA-less promoters. Genes \& Dev. 6: 1964-1974.

Zitomer, R.S. and C.V. Lowry. 1992. Regulation of gene expression by oxygen in Saccharomyces cerevisiae. Microbiol. Rev. 56: 1-11. 


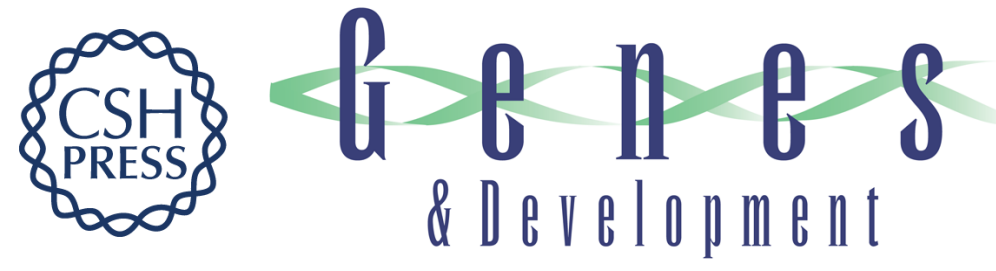

\section{Requirement of a corepressor for Dr1-mediated repression of transcription.}

$\mathrm{F}$ Mermelstein, $\mathrm{K}$ Yeung, J Cao, et al.

Genes Dev. 1996, 10:

Access the most recent version at doi:10.1101/gad.10.8.1033

References This article cites 79 articles, 35 of which can be accessed free at:

http://genesdev.cshlp.org/content/10/8/1033.full.html\#ref-list-1

License

Email Alerting

Service

Receive free email alerts when new articles cite this article - sign up in the box at the top right corner of the article or click here.



